\title{
ACHIEVING MODERN SYSTEMS IN ACHIEVING SUSTAINABLE ARCHITECTURE IN EGYPT
}

\author{
Ahmed Al Hussein tohlob \\ Architectural Dept, Misr Institute for Engineering and Technology
}

\begin{abstract}
Construction technology has recently experienced several breakthroughs in the development of building materials and methods that have led to access to modern systems used in construction regardless of the negative effects on the ecosystem and the sustainability of these buildings. In the early 1970s, the first environmental conference called for sustainability And the interaction of the community with the environment in the presence of 112 countries, and the environmental conferences continued to call for sustainability, At the same time, architectural creativity did not stop on the traditional methods of design in terms of aesthetics of proportions and function. However, contemporary creativity has integrated science and modern technology techniques into architecture both at the level of design, construction, execution or building materials, while achieving the best product for the welfare and comfort of the building user And the interest of the environment and the sustainability of its resources. Therefore, the research is concerned with new and innovative science and technology that can provide effective scientific and practical solutions to reach buildings to the highest degree of sustainability globally.
\end{abstract}

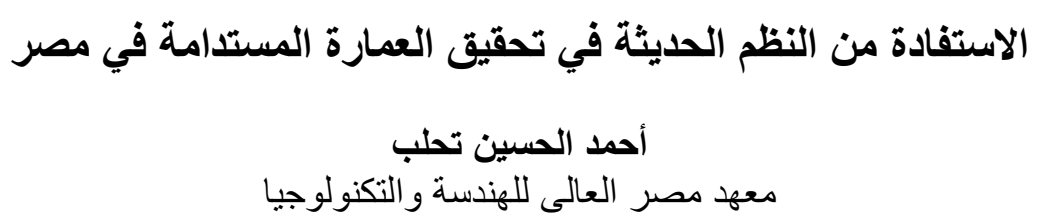

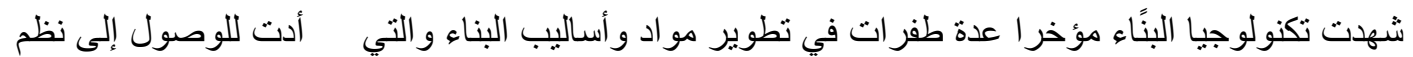
الملخص:

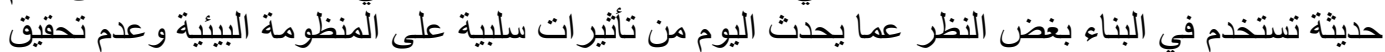
استدامة هذه المباني، وفي بداية السبعينات

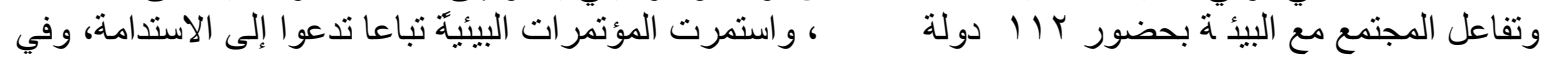

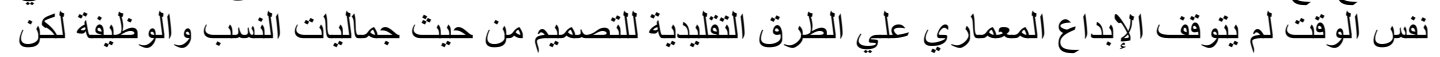

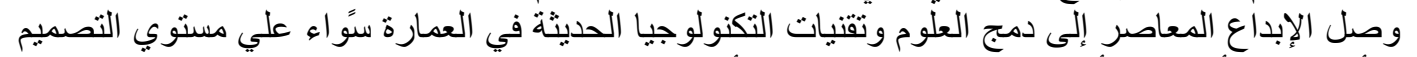

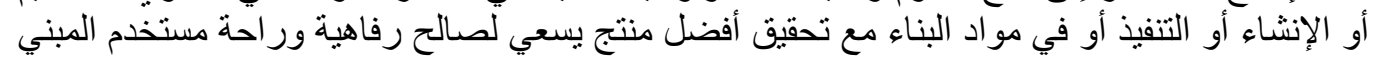

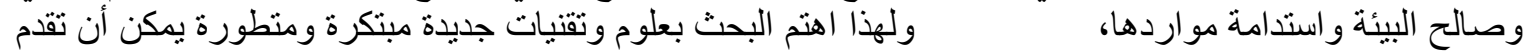

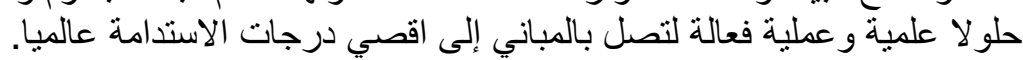

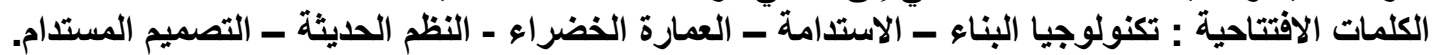




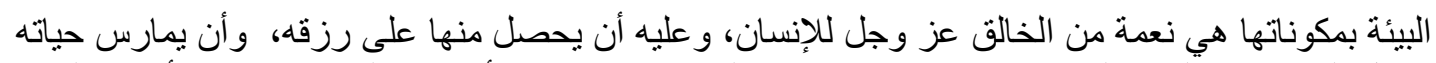

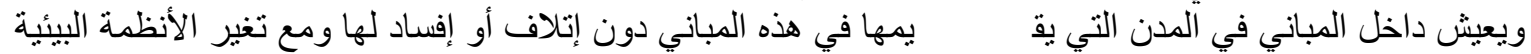

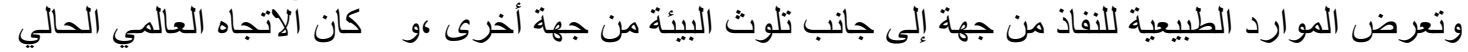

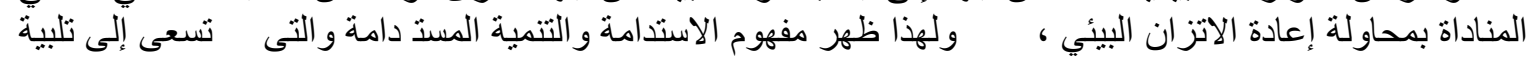

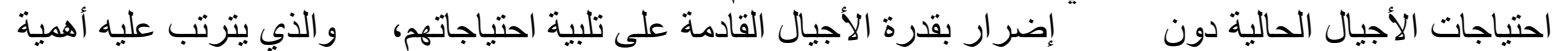

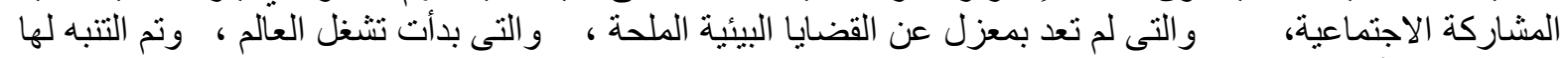

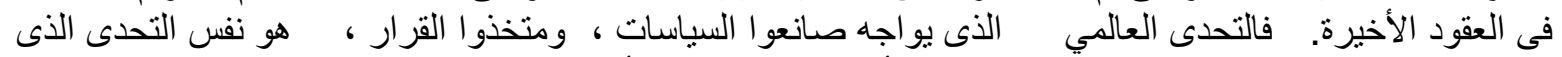

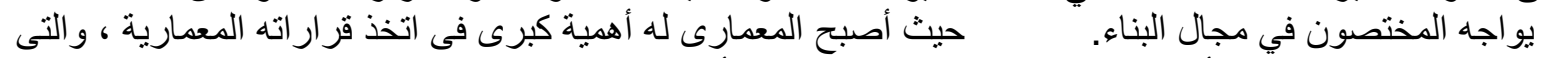

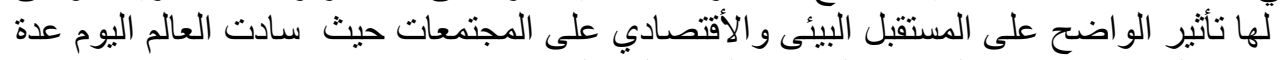

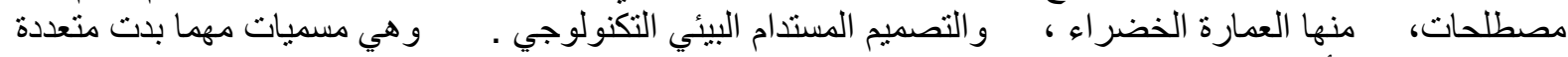

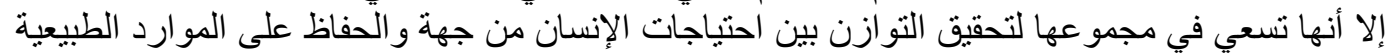

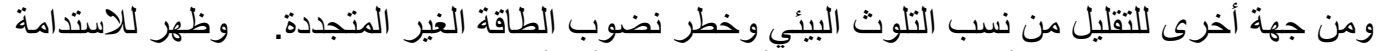

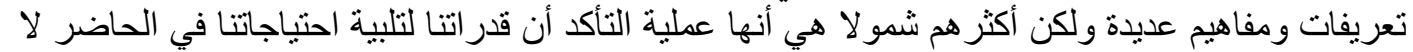

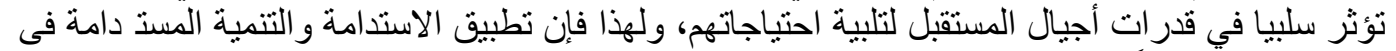
بدأت الدول المتقدمة و الصناعية و الكبرى فى اعتماد مفاهيم الاستدامة

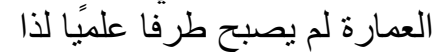

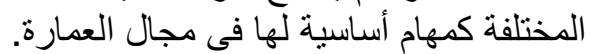
الاشكالية البحثية : البمانية

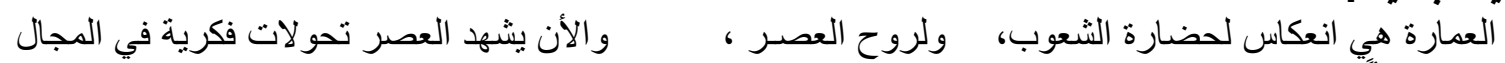

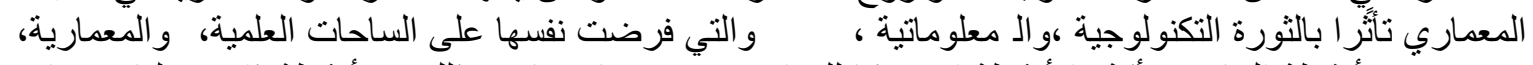

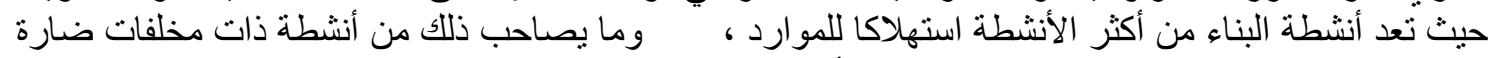

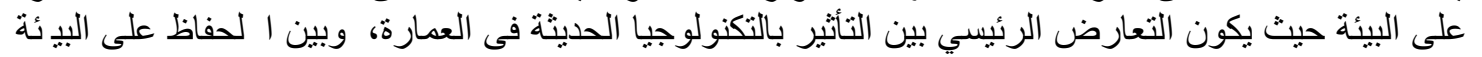

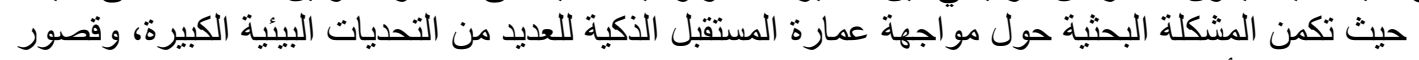

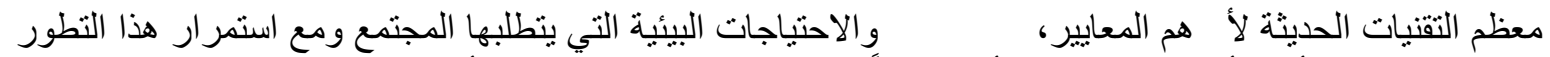

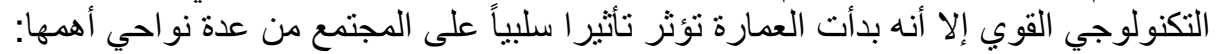

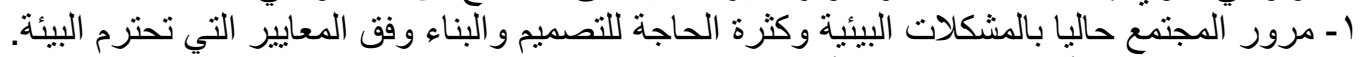

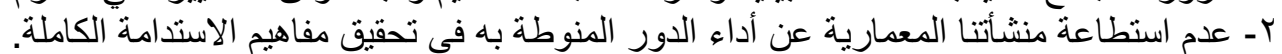

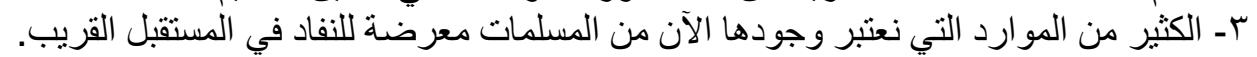

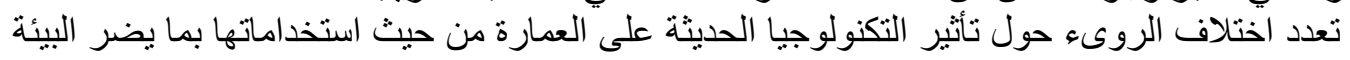
$-\varepsilon$

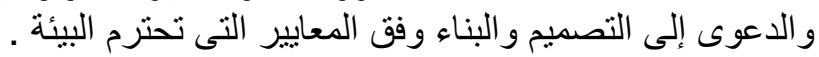

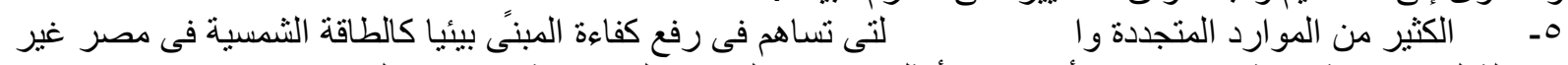

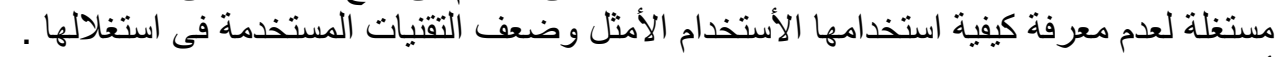

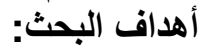
يتلخص الهدف الرئيسي للبحث في التركيز علي التغيرات التي ستحدثها النظم الحديثة (تكنولوجيا النانو) بما وصلت إليه التهايه

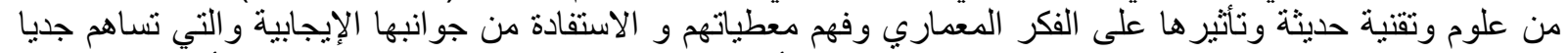
في رفع الكفاءة البيئية لمبانيها كما يسلط الضوء علئه علي مدي تأثير تكنولوجيا النانو علي الفكر المعاصر للأنماط المعمارية المختلفة العالمية و المحلية.

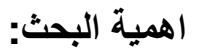
يرجع أهمية البحث فى محاولة إستغلال إمكانيات الموارد المتجددة (الطاقة الثمسية ) من التكنولوجيا الحديثة في العمارة

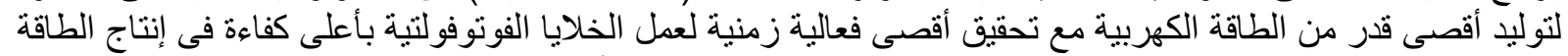

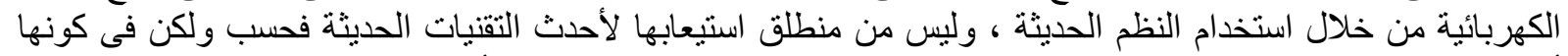

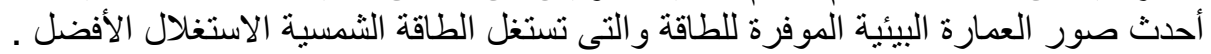

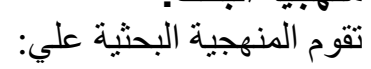
ا-المنهج النظري : : عرضئ مفهوم و أساسيات الاستدامة و العمارة المستدامة و أهم مبادئ و أسس التصميم المستدام و الصيغة التنفيذية لتحقيق العمارة المستدامة.

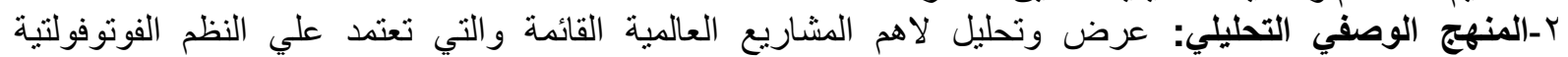

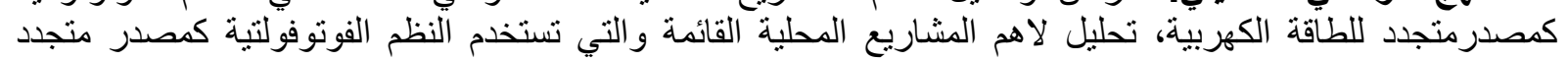
للطاقة الكهربية. 


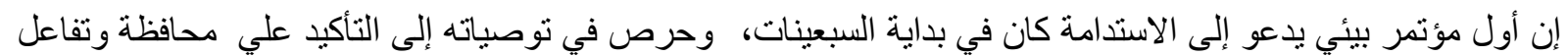

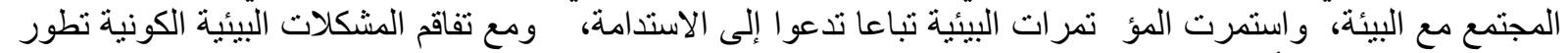

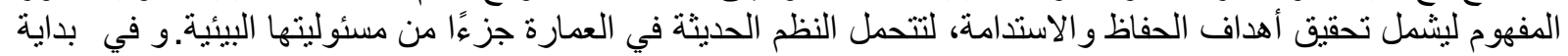

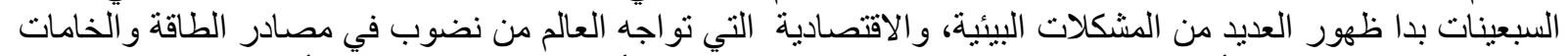

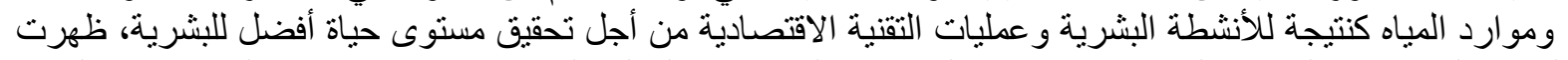

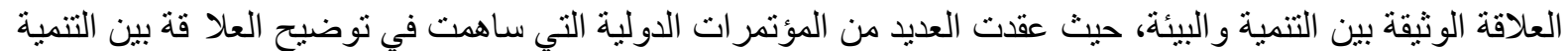

و البيئة و إدر الك منظومة بينة الفنة

مضدونين أساسيين، أنها ليست قاصرة على عدد من العلوم

التنمية البيئية بأبعادها المختلفة ،وتشمل هذه التنمية (البيئية)

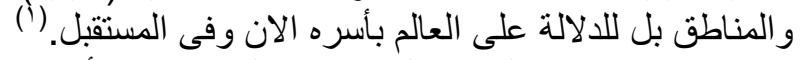

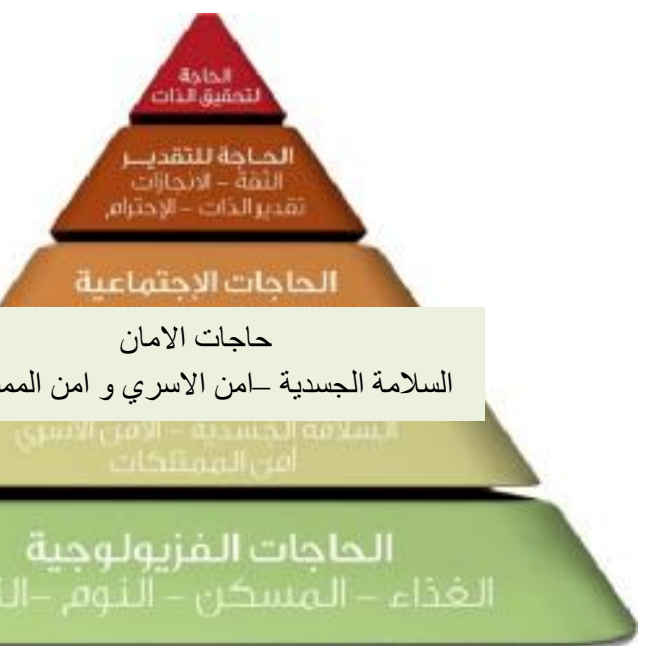

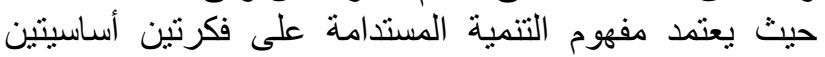
تتحقق من خلالهما وهى:

مفهوم الاحتياجات والذى يتضمن السعي إلى تحقيق مستوى حياة مرضى لجمئ النيع الناس.

• • الحدود القصوى والذى بتضنمن حدود تلبية البيئة

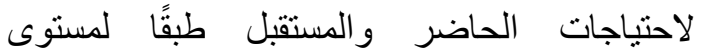
التكنولوجيا، و النظم الاجنماعية.

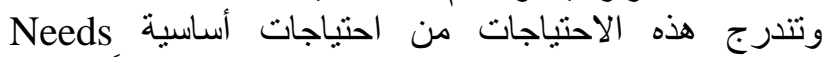
كالمأكل والمشرب والملبس إلى احتياجات فرعية طبقًا لتقسيم

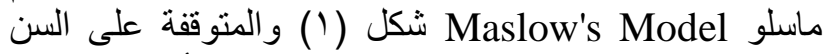

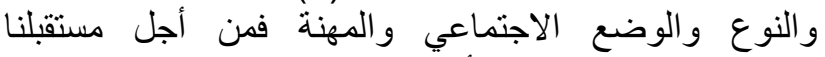
المشترك سيكون من الأفضل إثباع الضرغن الضروريات وتقليل

\section{r محاور التنمية المستدامة}

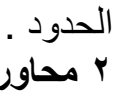

شكل (1): يوضح الاحتياجات الإنسانية طبقا للأولويات

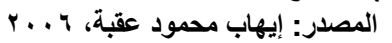

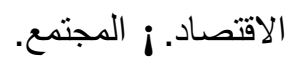

المستدامة لابد من ارتباط هذه المحادئه

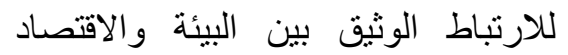
الاجتماعية، حيث تلقوم فكرة الاستدامة لإنة

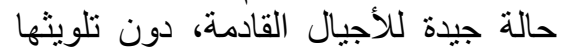

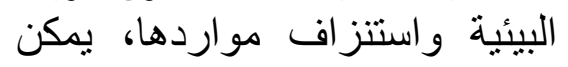
تطبيق وسائل تحقيق التنمية

\section{البيئة} البيئة من خلال تقليل المخلفة البئة والانبعاثات البيئة وتقليل فليل الآثار

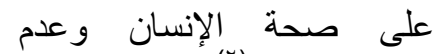

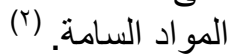

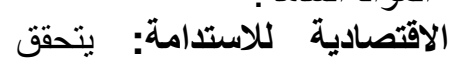
خلال خلق أسواق وفرص للأمة للتنمية

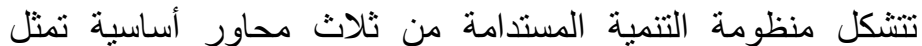
الدعائم الرئيسية لها وباختلال أحدهم تتأثر الأهداف الرئية الرئيسية للتنمية

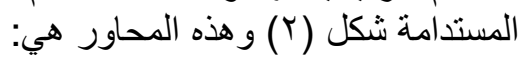

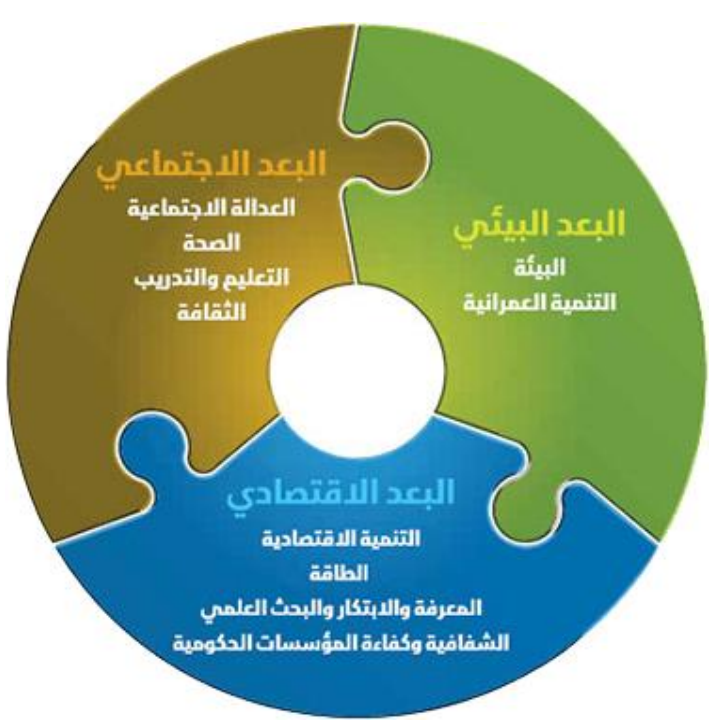

○ البيئة. ولنجاح عملية التنمية وتكاملها ومستوى الحياة على ترك البيئة في و وإفساد الأنظمة فئة ذلك من خلافل المستدامة بأبعادها ß الأبعاد

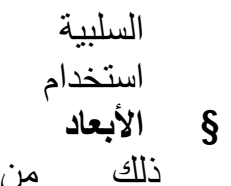
ذلك

وتخفيض التكلفة وتحسين الأداء و استخدام الطاقة. 
B الأبعاد الاجتماعية للاستدامة: من خلال الاهتمام بصحة الأنسان وسلامته و التحكم في التأثير على المجتمعات

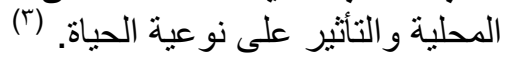

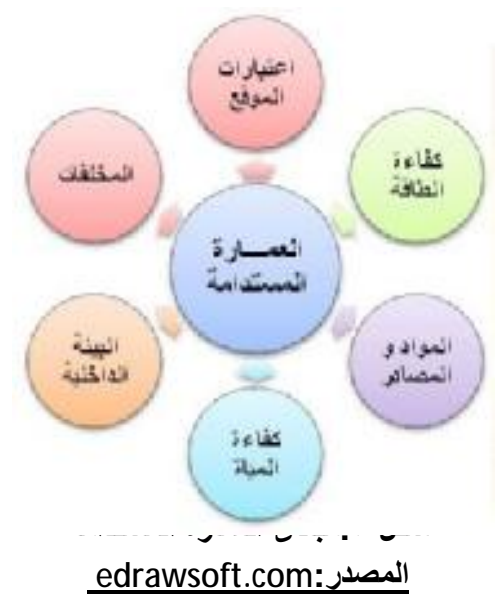

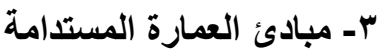

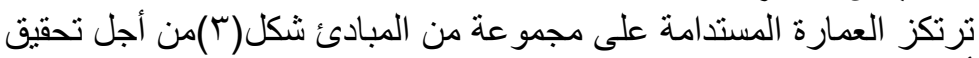

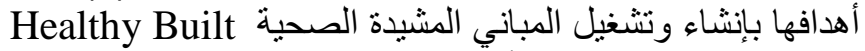

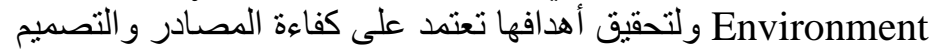

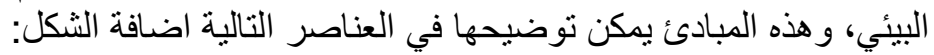

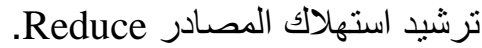

أعادة استخدام المصادر Reuse.

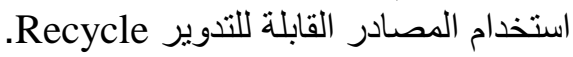

حماية البيئة Protection Nature.

التخلص من السموم و الملوثات Toxics Disposal

تطبيق تكلفة دورة الحياة الكاملة Economic Life Cycle.

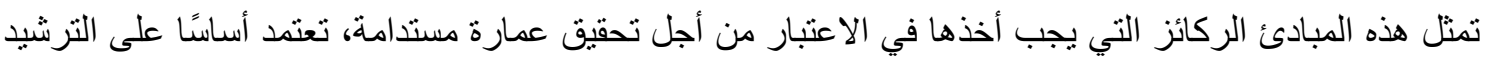

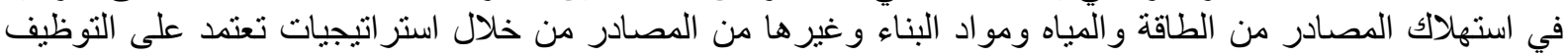

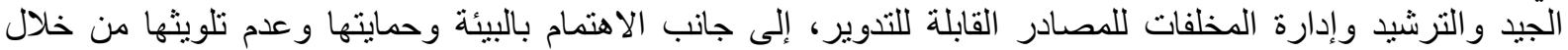

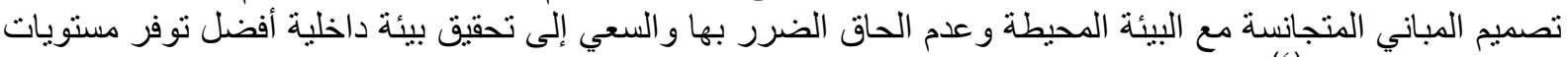

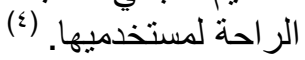

\section{• • الصيغة التفيذية لتحقيق التصميم المستدام}

لقد اجتهد كثير من رواد الاستدامة في العمارة وعديد من التنظيمات المهنية و الأكاديمية في تطوير وسائل تحقيق

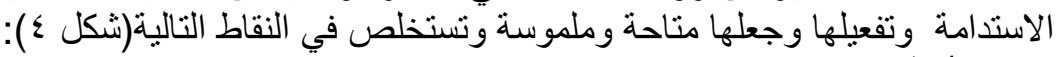

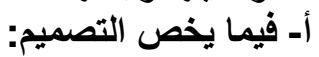

تصميم المباني ينبغي أن يكون مؤديا دوره طول الوقت ويكن ويكون مقاوم للكوارث الطبيعية وتحقيق المبني أقصي

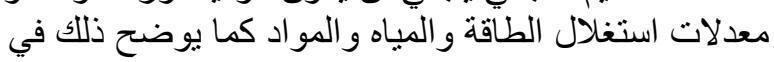

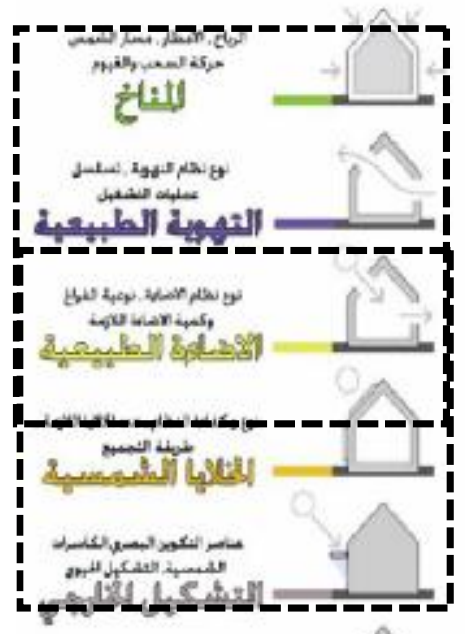

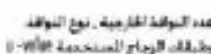

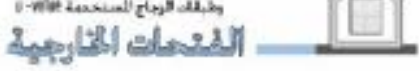
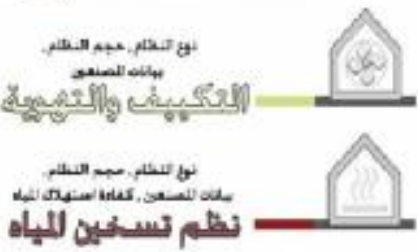

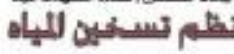

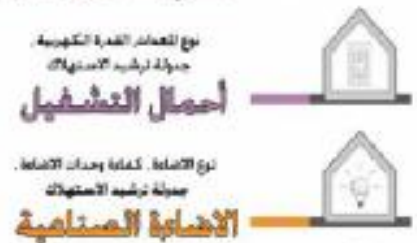

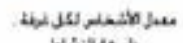

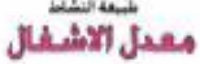

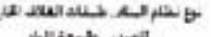
مباله

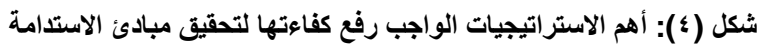

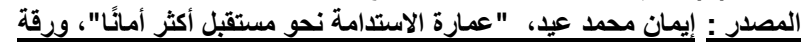

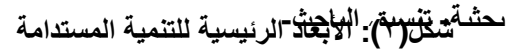

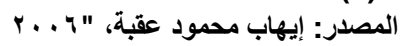

$$
\begin{aligned}
& \text { B } \\
& \text { قبول المبني للتعديلات و التوسـع مستقبلًا. } \\
& \text { أن بتجنب الإضرار الصحية في تصميم المبني. } \\
& \text { ب- فيما يخص الموقع: }
\end{aligned}
$$

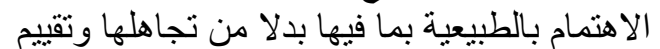

وتقدير كل ثرو اتها ،و الاستفادة من إعادة استعمال المباني

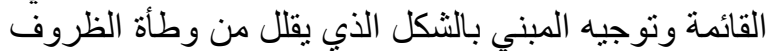
البيئية عليه.

فلقد تغيرت كثير ا نظرة كبار المعماريين في العالم

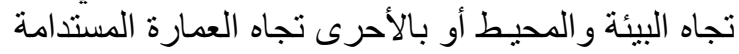
فتغيرت معها الكثير من النئ (Sustainable architecture) المفاهيم المعمارية. إلا أن التحدي الذي يو اجه المعداريين

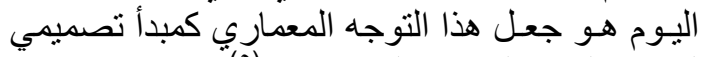

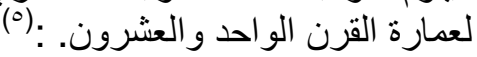

؛ ـ استراتيجيات تحقيق كفاعة الطاقة. 
تتحقق كفاءة الطاقة في البناء من خلال تطبيق استر اتيجية متكاملة تسعى إلى ترشيد استهلاك الطاقة وكفاءة

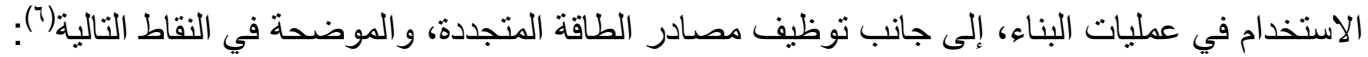

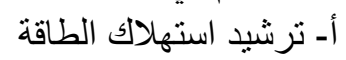

أ ترشيد الطاقة المستهلكة في المباني بجميع أشكالها كعمليات التبريد والتدفئة والإضاءة من خلال تصميم بيئي يتلاءم و البيئة المحيطة.

B الاستخدام الأمثل للتصميم الثمسي السالب ومراعاة توجيه والثكل وأماكن الفتحات واختيار عناصر تتسيق الموقع الملائمة ومتطلبات الاستهلاك ألمبنى.

استخدام أغلفة المباني عالية الكفاءة باختيار خامات الحوائط والأسقف والعناصر الأخرى وتحقيق متطلبات

العزل و الكفاءة و المتانة.

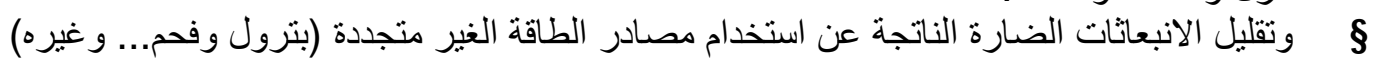

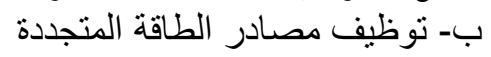

توظيف مصادر الطاقة المتجددة، وإدماجها في تصميم المبنى كالإضاءة الطبيعية Day lighting م التصميم

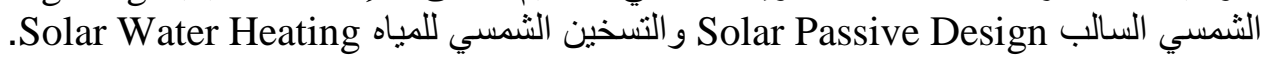
تو استخدام الخلايا الثمسية Photovoltaic Cells المولدة للطاقة الكهربية من الطاقة الثمسية النظيفة وإدماج

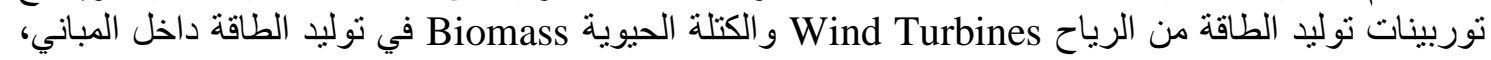

شكل (0)، (T) (1).

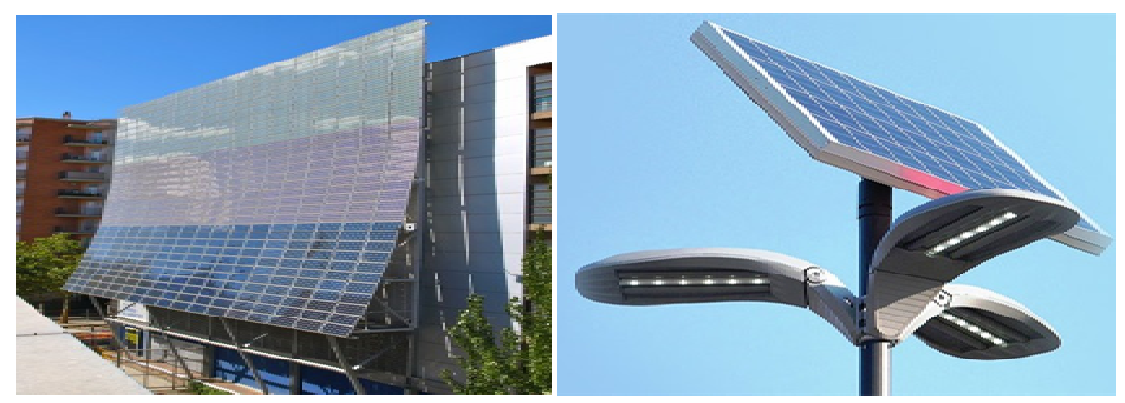

(0): استخام الخلايا الثمسية بطرق متعددة لتوليد الطاقة الكهربية

www.digital.argaam.com:المصنيان
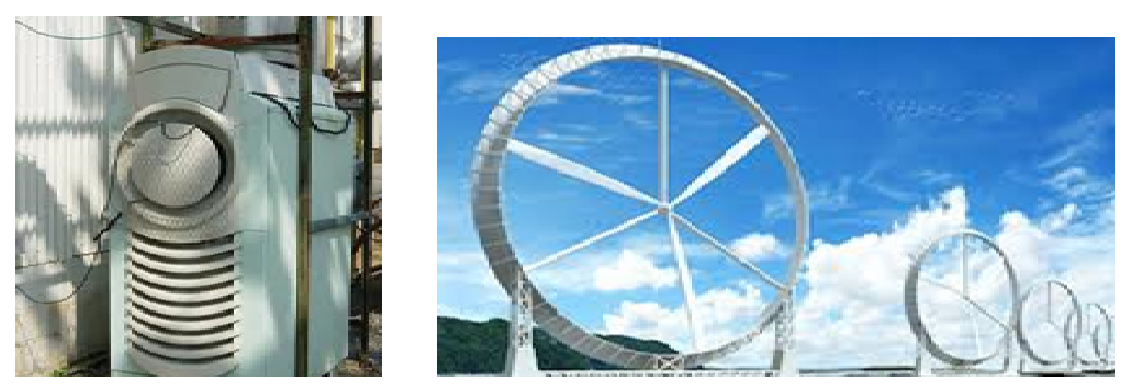

شكل (؟) توربينات توليد الطاقة من الرياح و الكتلة الحيوية

arabiaweather.com:المصناح

هـ المفهوم المتكامل لتكنولوجيا وعلم النانو

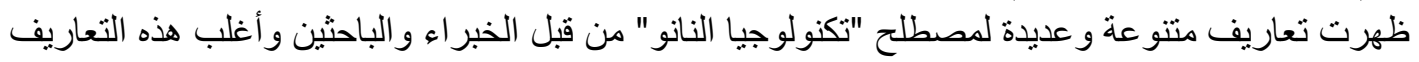

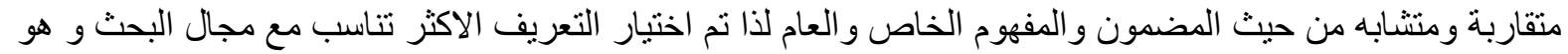

مفهوم النانوية "هو البحث و السبطرة أو التحكم في بنية المادة الداخلية عند المقياس الذري و الجزيئي عن طريق كالتالي: مابن

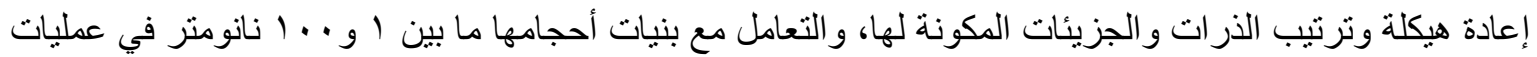

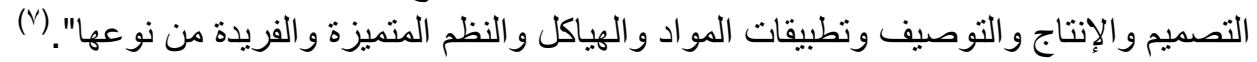




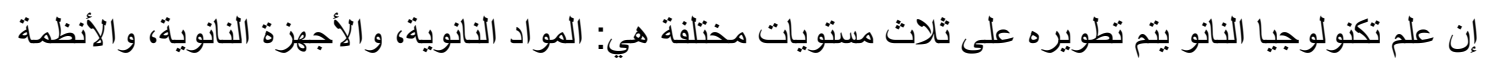

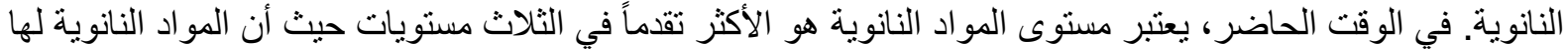

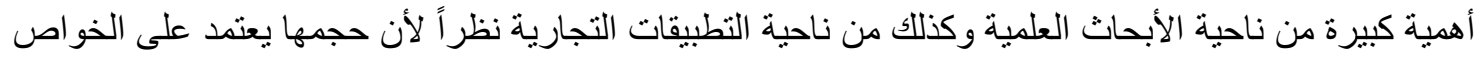

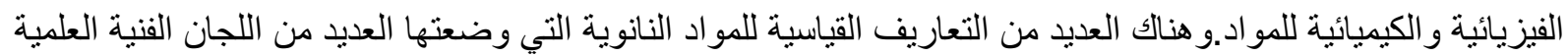

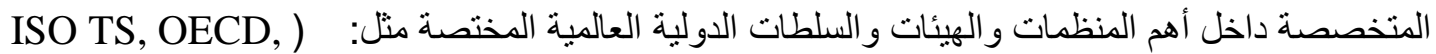

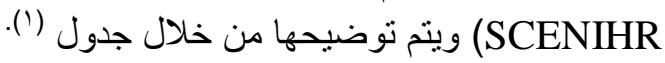

جدول ( ) : تعاريف المواد النانوية المعتمدة من المنظمات العالمية

\begin{tabular}{|c|c|}
\hline مواد ذات بعد خارجي بمقياس النانومتر أو ذات بنيان داخلي أو سطحي بمقياس النانومتر. & 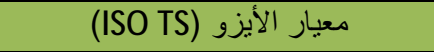 \\
\hline 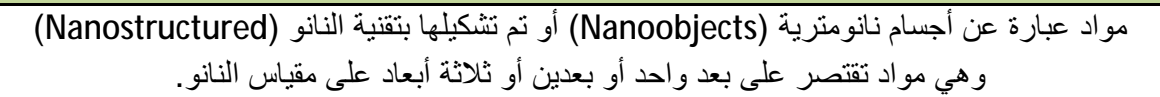 & منظمة التعاون والتتمية الاقتصادية \\
\hline 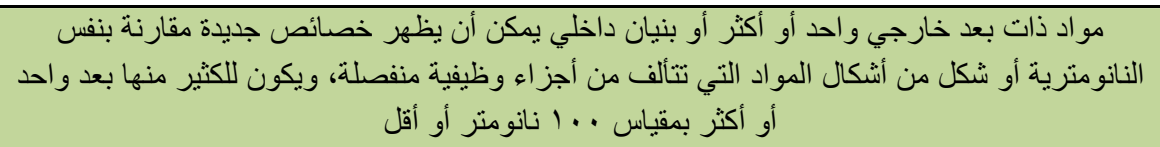 & 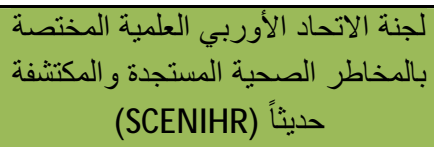 \\
\hline 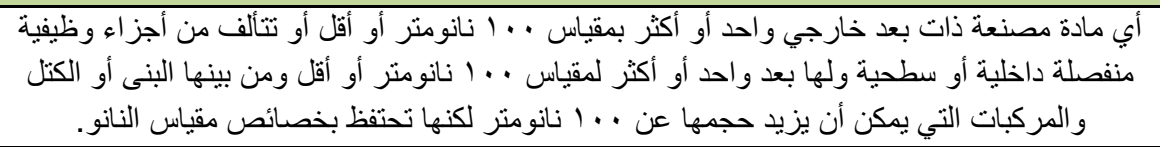 & الاتحاد الأوربي: إعادة صياغة القانون \\
\hline 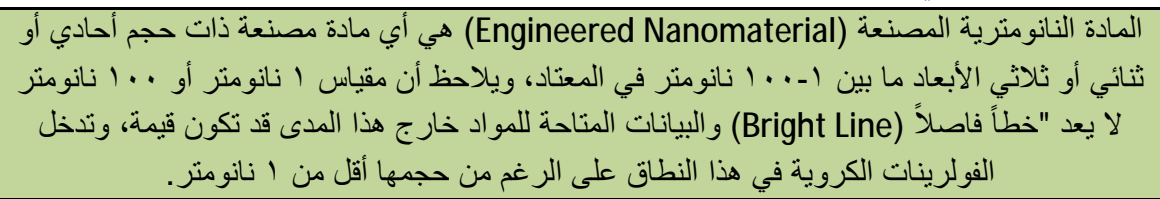 & المجلس الأمريكي للكيمياء (ACC) \\
\hline
\end{tabular}

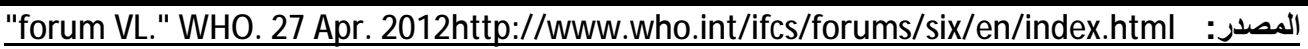

ومن خلال المصطلحات السابقة نجد أنها تشترك جميعاً في أنها "مواد ذات بعد خارجي واحد أو أكثر على مقياس

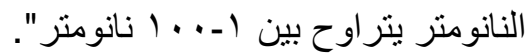

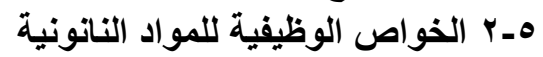

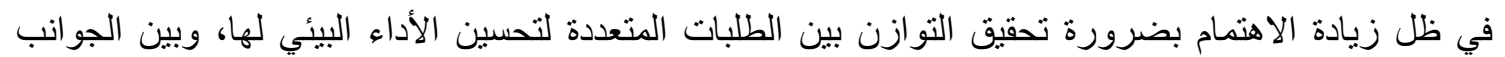

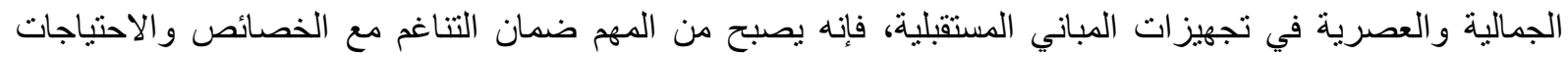

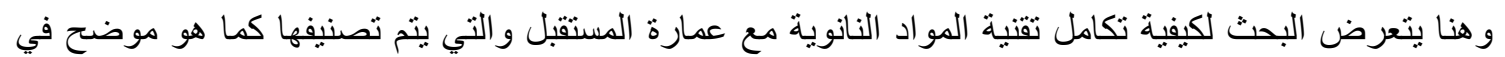
الوظيفية للمو اد.

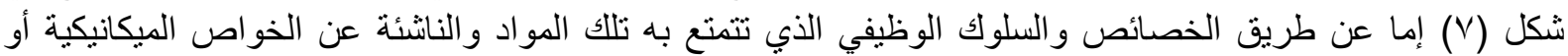
الكيميائية أو الحرارية أو البصرية التي تمتلكها أو الخواص التي يطلق عليها مسمى الخواص التئ الذكية" والتي تشمل

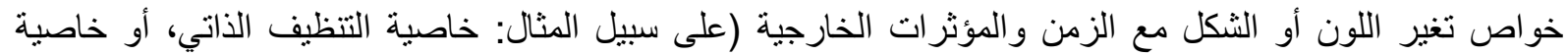

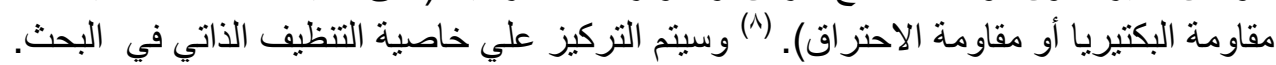

د النانونية الخواص الوظيفية للمو اد النانونية

\begin{tabular}{|c|c|c|c|c|c|}
\hline 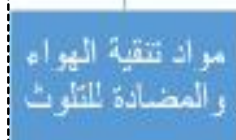 & 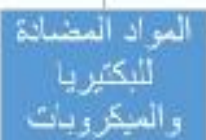 & وبسيكة إلتفليف & الثيقاصن النكية & 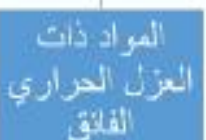 & الأمراد ذانية \\
\hline
\end{tabular}


في مجال العمارة تعتبر عمليات التنظيف الأولية والمستمرة لنوافذ أو أسطح الواجهات الخارجية للمباني أو الخلايا

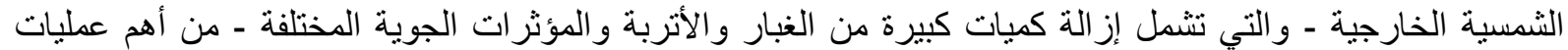

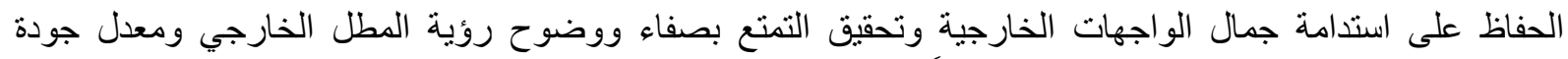

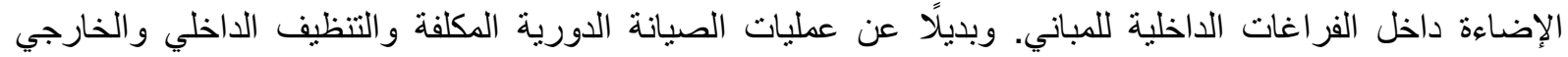

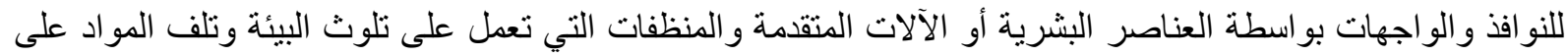

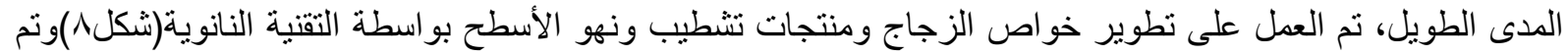

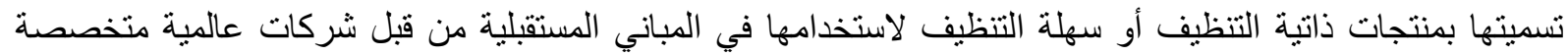

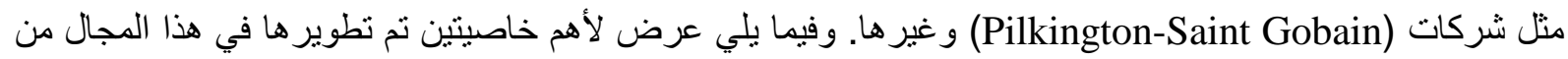
قبل المجمو عات البحثية في عدد من الجامعات و الثركات العالمية:
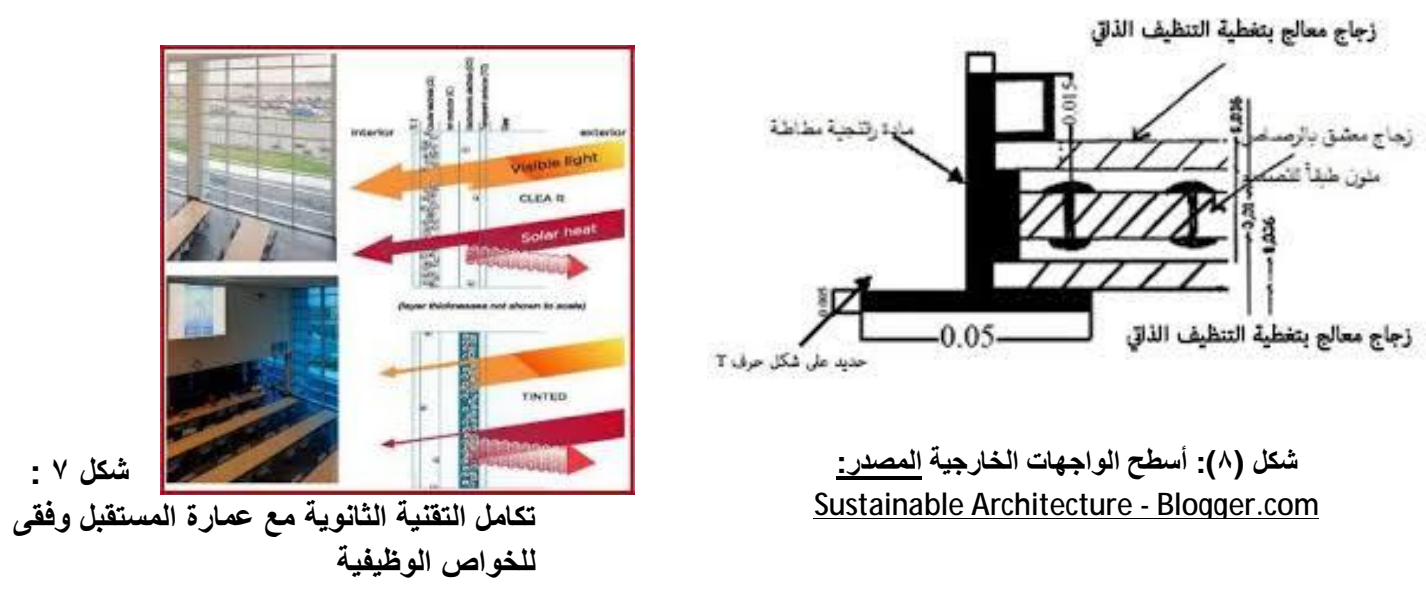

شكل (^): أسطح الواجهات الخارجية المصدر:

Sustainable Architecture - Blogger.com

المصدر الباحث

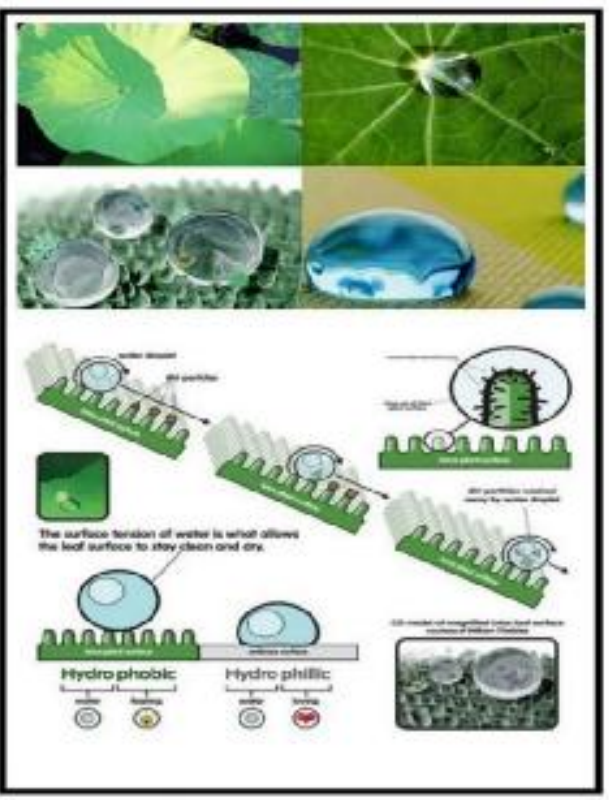

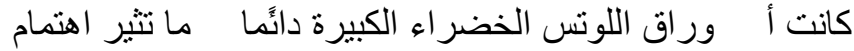

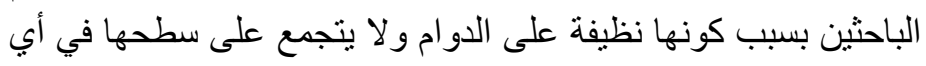

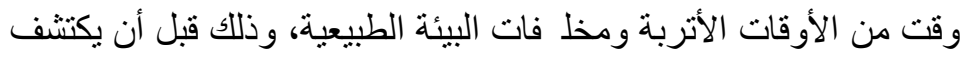

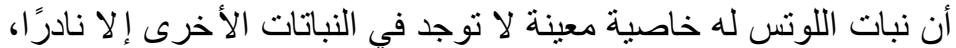

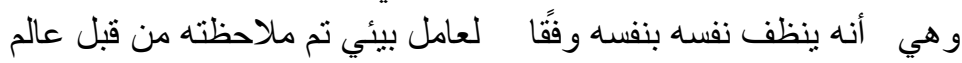
النبات الألماني ويلهام بارتلوت (Wilhelm Barthlott) تحت اسم

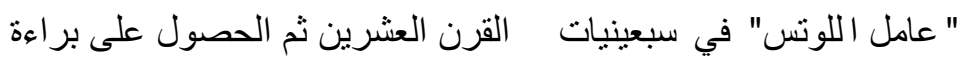
اختر اع في الجزيئات متناهية الصغر بت سجيل تلك الظاهرة بعد دراستها

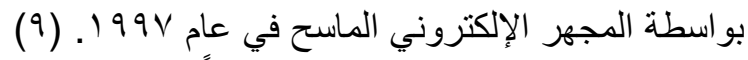

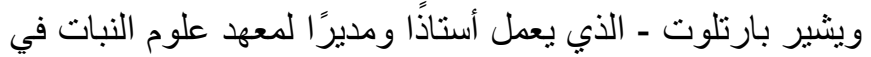

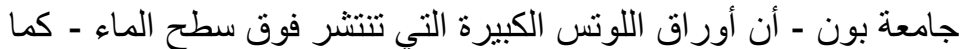

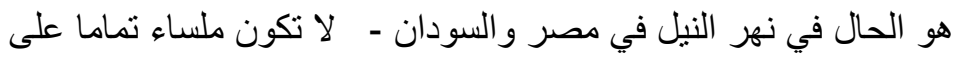

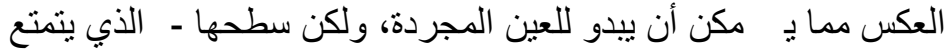

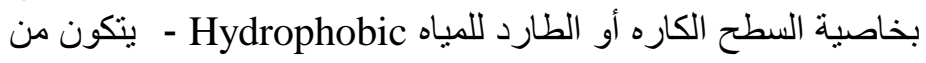
شعير ات وحبيبات صغيرة جدًا ودقيقة ذ ات مقاييس شبه متساوية نتر اوح

\footnotetext{
شكل (9): طبيعة السطح الخارجي الطارد للمياه لأوراق اللوتس بالمقياس النانوي والتي تسمي بتأثير اللوتس لأنس

Lotus effect. 16 Feb. 2013 المصنير:

http:// www.ryannygard.com/files/images/5 lotus.jpg
} 


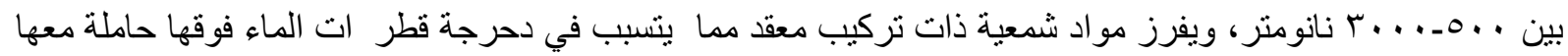

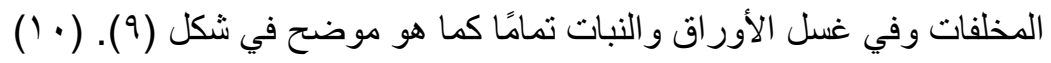

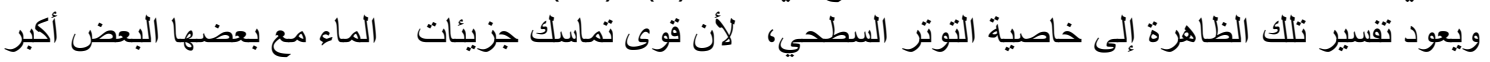

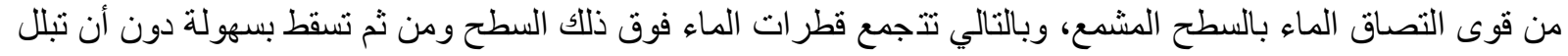

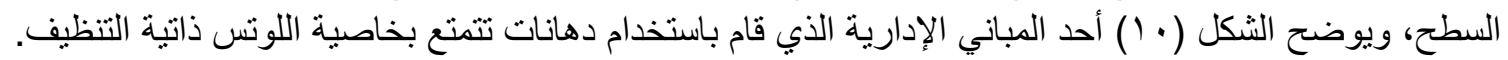

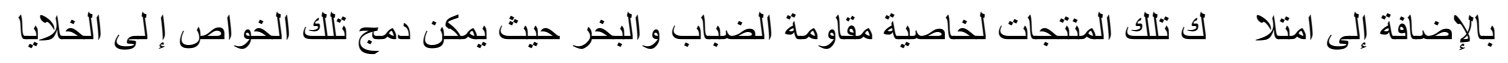

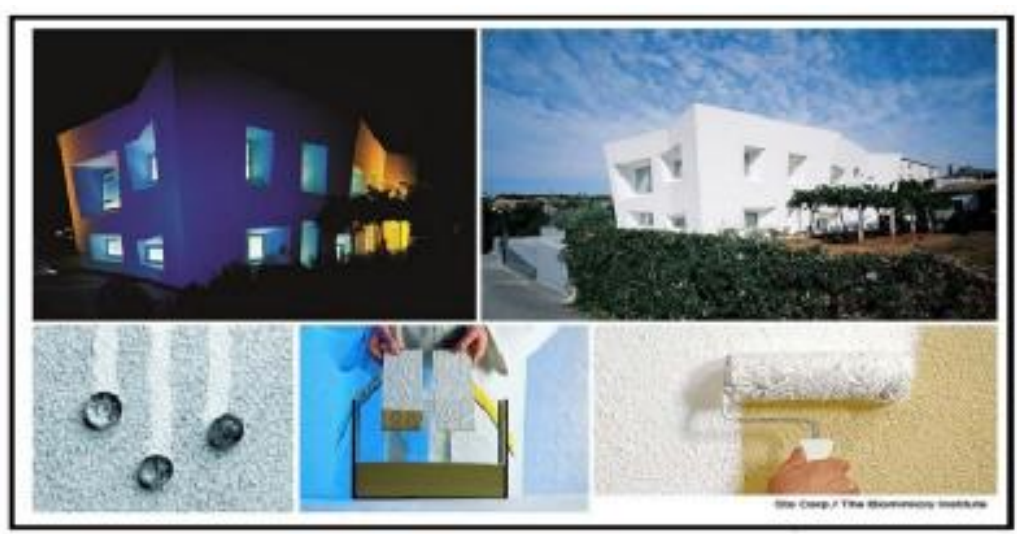

شكل (• (1): مبنى شركة

ץ... \ Doro, Valentina. "4aMagazine: A sustainable talk with the lighting designer Dean Skira". 16 Feb. 2013 http://www.new4amagazine.com/2012/02/sustainable-talk

ت عتمد عملية التحفيز على مادة تعمل على زيادة معدل

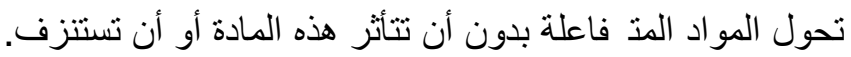

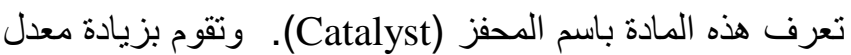

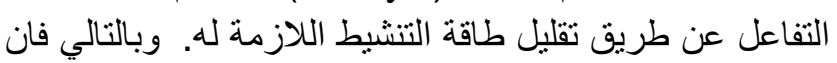
عملية التحفيز الضوئي هي عبارة عن تفاعل يستخدم فيه الضوء

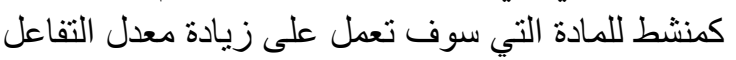

$$
\text { الكيميائي بدون أن يكون لها دور في التفاعل نفسه. }
$$

وتعد مادة ثاني أكسيد التيتانيوم من أهم التهو المواد أنشباه

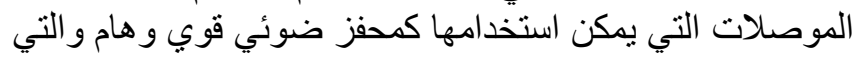

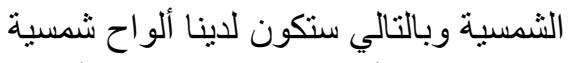

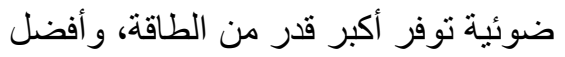

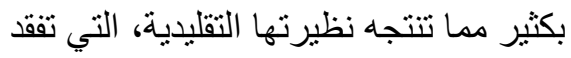

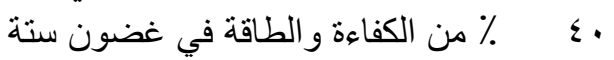

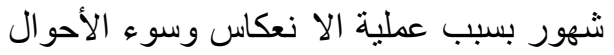

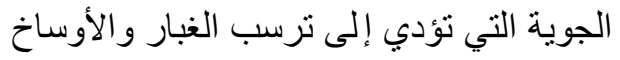
على أسطح تلأك الألو إح مما يقلل من كفاءتها.

\section{خاصية التحفيز الضوئي:}

كلمة تحفيز ضوئي Photocatalysis

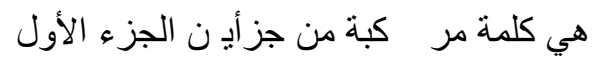
Photo Catalysis

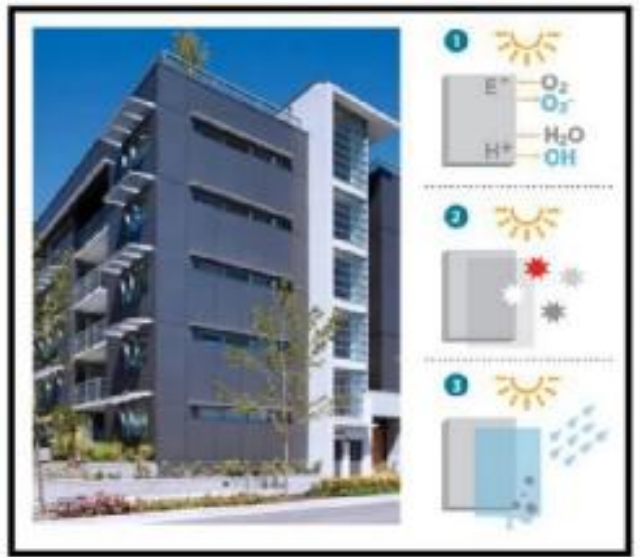
يرمز لها

شكل (1'): آلية عمل خاصية التحفيز الضوني Woody, Todd. "Air Freshener." Forbes Magazine. 06 Jun 2011. 6 Fib. 2013

$$
\begin{aligned}
& \text { أكسيد التيتانيو الأشعة فوق البنفسجية من مصدر ضوئي خارجي }
\end{aligned}
$$

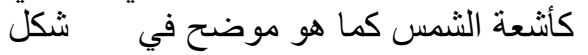

$$
\begin{aligned}
& \text { فإن طاقة الأشعة فوق البنفسية تكون كافية لتحريز إلكترون في } \\
& \text { وفجوة موجبة }
\end{aligned}
$$

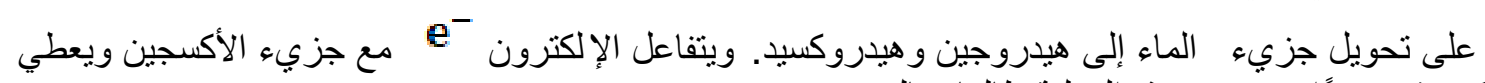

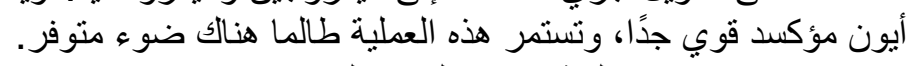

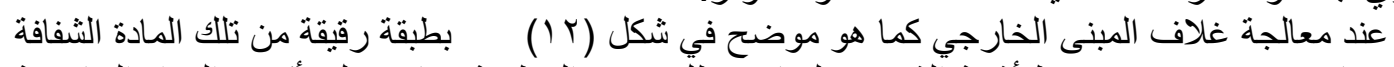

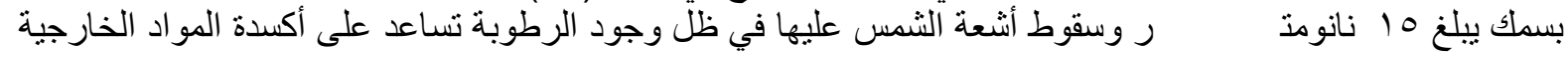

(10) Somov, Pavel G. The lotus effect: Shedding suffering and rediscovering your essential self. Oakland, CA: New Harbinger Publications, 2010.

(11) Somov, Pavel G. The lotus effect: Shedding suffering and rediscovering your essential self. Oakland, CA: New Harbinger Publica ons, 2010. 


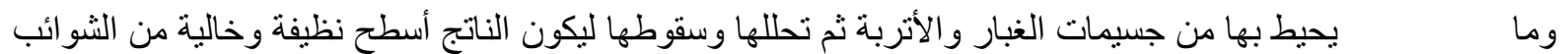

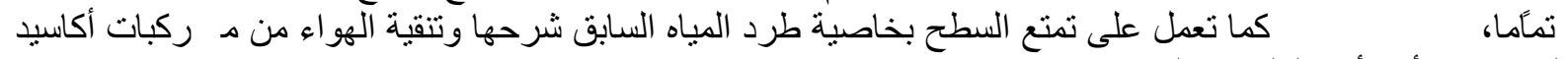
النيتروجين أحد أهم الملوثات البيئية.

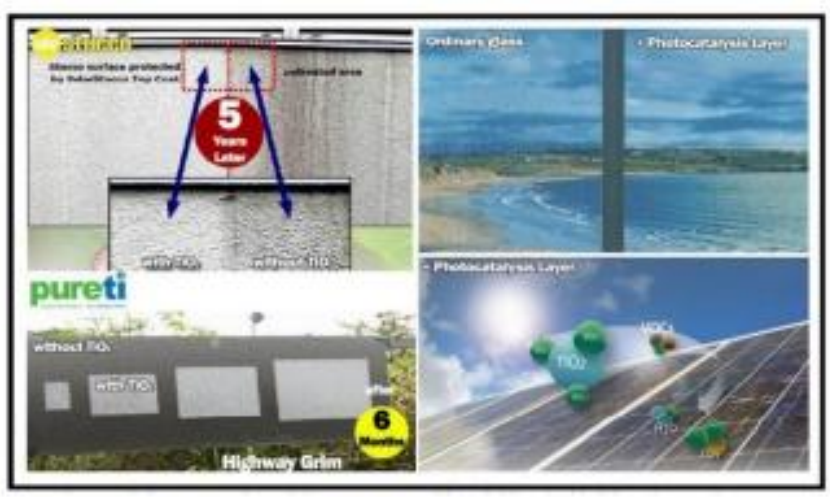

إن تثييد الواجهات الخارجية للمباني

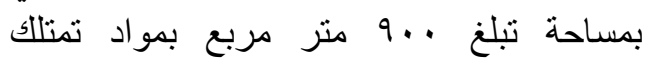

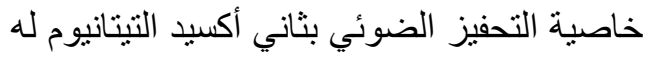

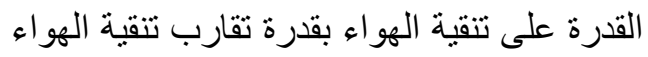

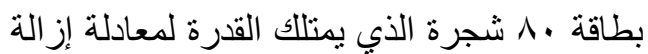

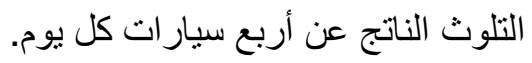

تعمل المنتجات التي تتمتع بخاصية التحفيز

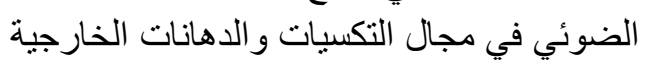

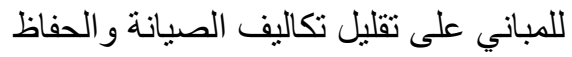

شكل (r ا )): التطبيقات التجارية الحالية والمستقبلية المتوقعة لمنتجات

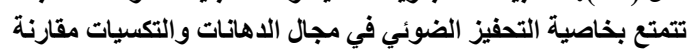
بالمنتجات التقليدية في القدرة على الحفاظ على نظئ نظافة الأسطح الخارجية

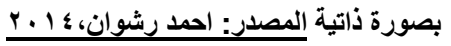

الخاصة بالمباني بمقدار الثلث إلى النصف من إجمالي

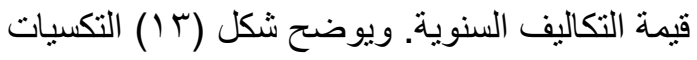
الخاصة بو اجهات مركز محمد علي كلاي الثقافي Muhammad Ali Center MAC الأمريكية
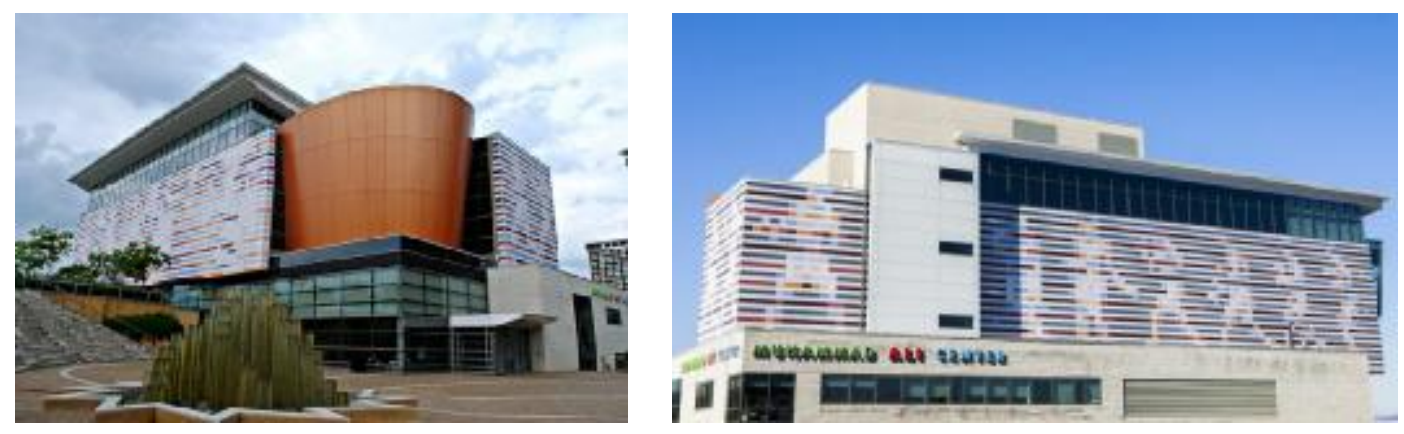

شكل (T) (1): تكسيات الواجهات لمركز محمد علي كلاي الثقافي Muhammad Ali Center MAC بولاة كنتاكي الأمريكية

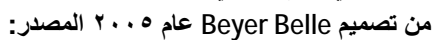

"Muhammad Ali Center". Entertainment/Venues Precision Walls. 16 Feb. 2013 http://www.precisionwalls.com/qallerv/entertainment-venues/muhammad-ali-center/print

Beyer من من تصميم Belle عام ه . . r و الذي ساهم في تحسين بيئته المحيطة و التقليل من معدلات التلوث بها.

\section{7-النظم الحديثة في العمارة وبناء الفكر المعماري}

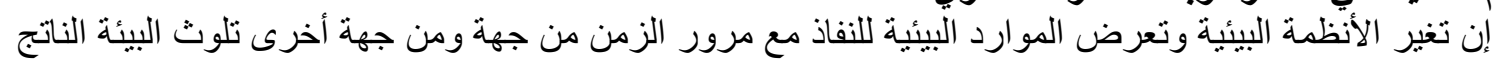

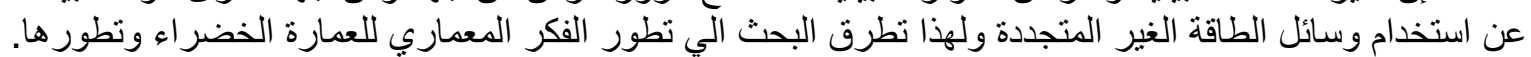

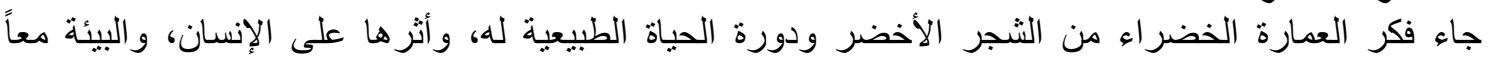

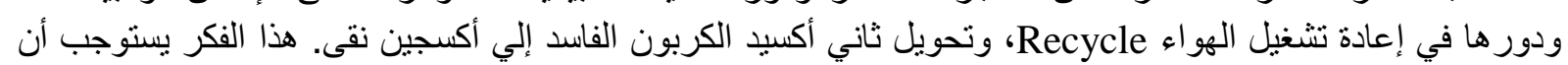

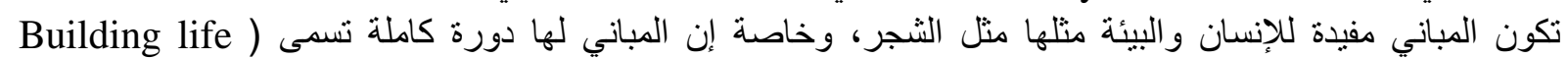

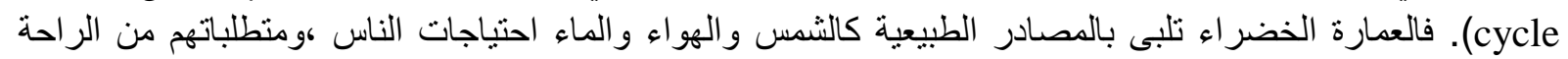

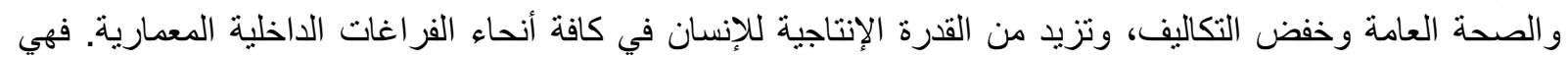


تفيد المحيط البيئي بقدر ما تستفيد منه، فهي لا تضره بنفاياتها وتصل إلى وسيلة لتدويرها والاستفادة منها فينعدم التأثير

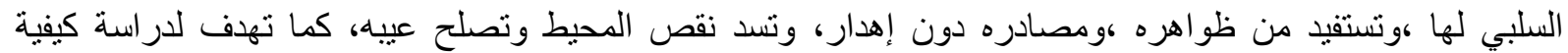

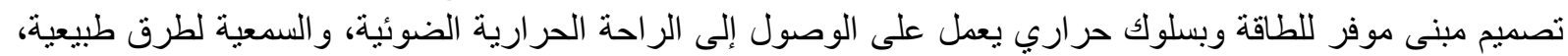

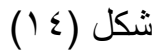

فالعمارة الخضراعِ هي:" بناء منظومة وظيفية منواكبة مع محيطها الحيوي ونطاقها الأيكولوجي من خلال

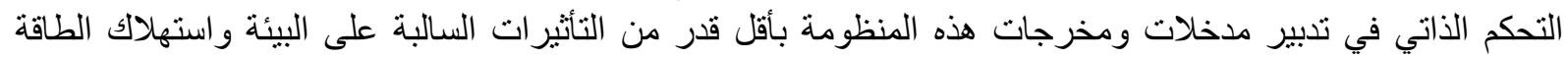
سواء عند بناء أو تشغيل أو هدم هذه المنظومة مما يحقق كفاءة أداء الوظائف والأنشطة المستهدفة وبتعبير معماري التئي

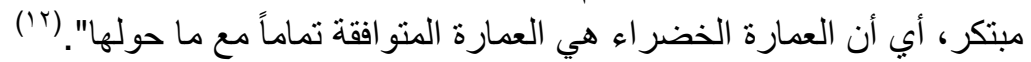
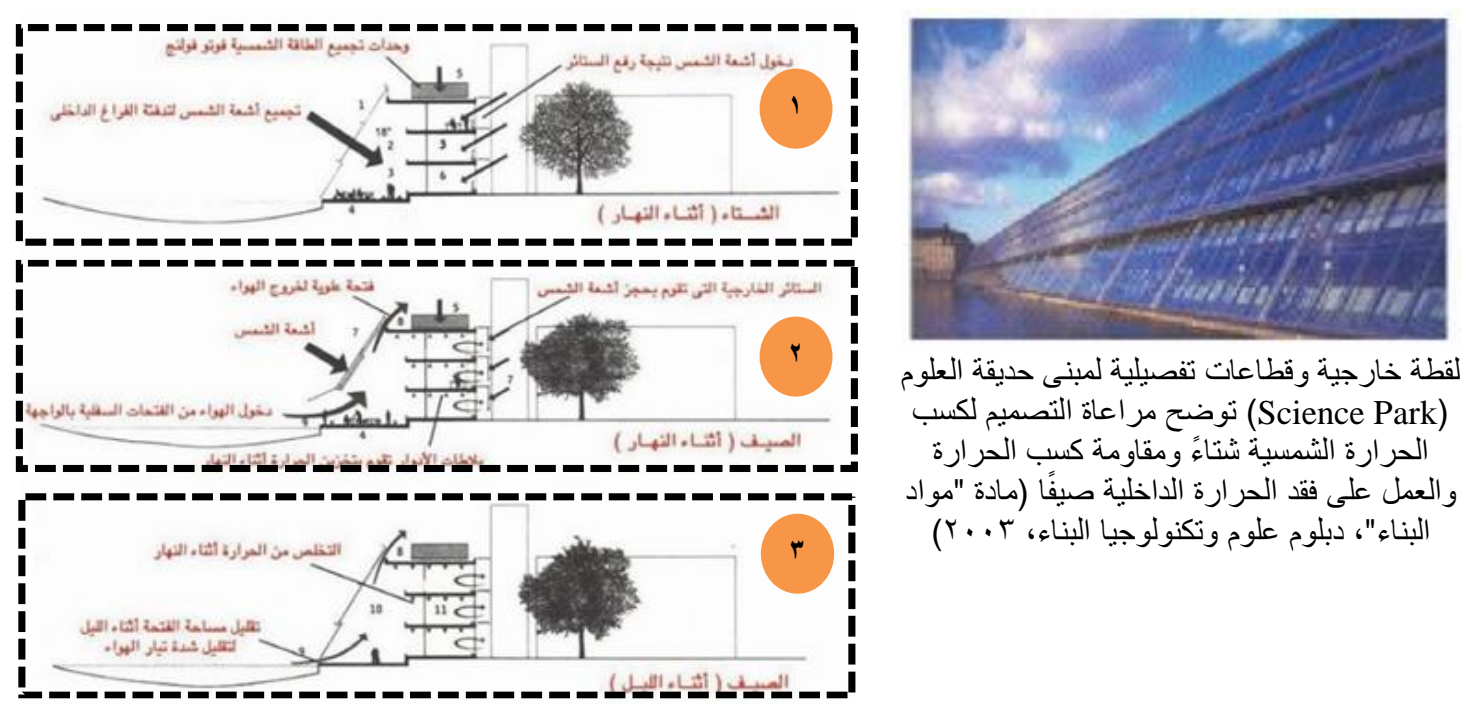

لقطة خارجية وقطاعات تفصيلية لمبنى حديقة العلوم

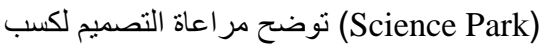

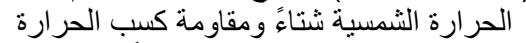

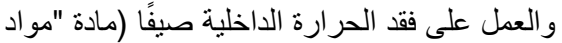

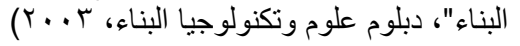
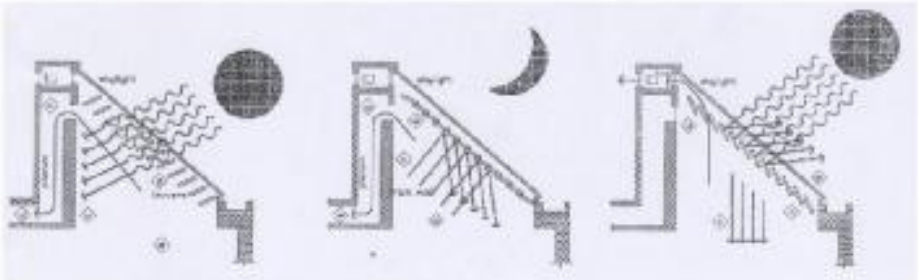

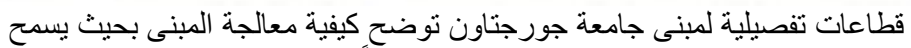

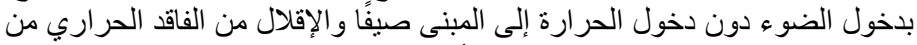
خلاء السقف الزجاجي شتاءً (أسامة عبده، العمارة الخضر الخاء)
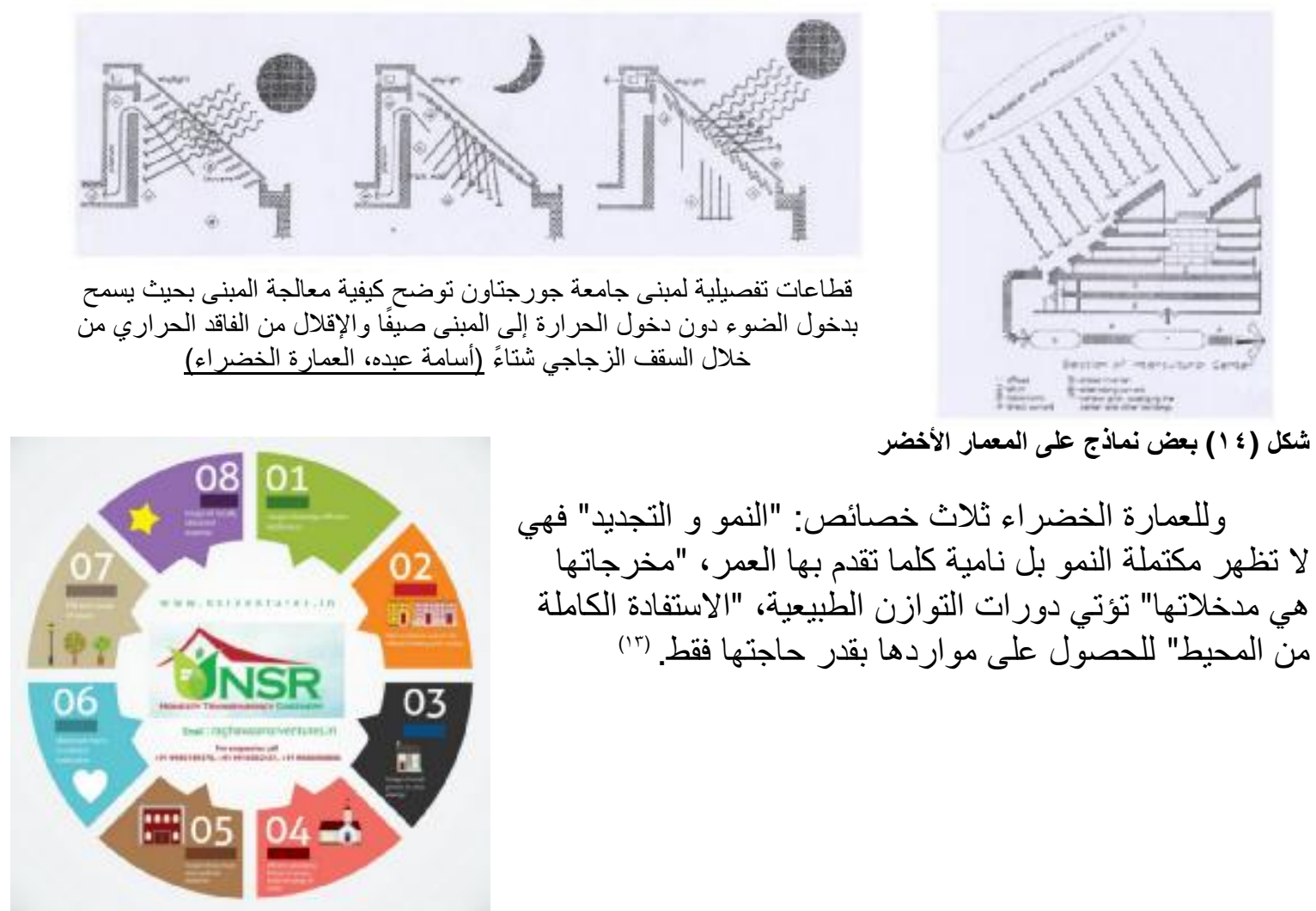

وللعمارة الخضر اء ثلاث خصائص: "النمو و التجديد" فهي

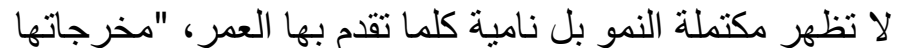

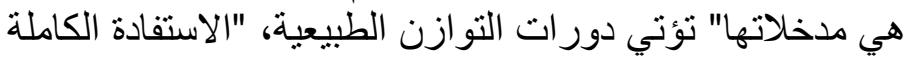

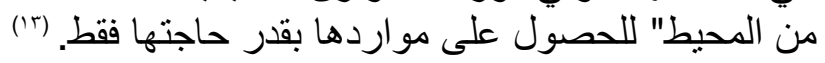

(T ا (1) مروة جودة فاضل بدر ان، "التحول بين المنطق و الإبداع كمدخل للعملية الفكرية بمنهجية العمارة المتو ائمة بيئياً، رسالة ماجيستير، كلية

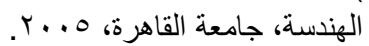




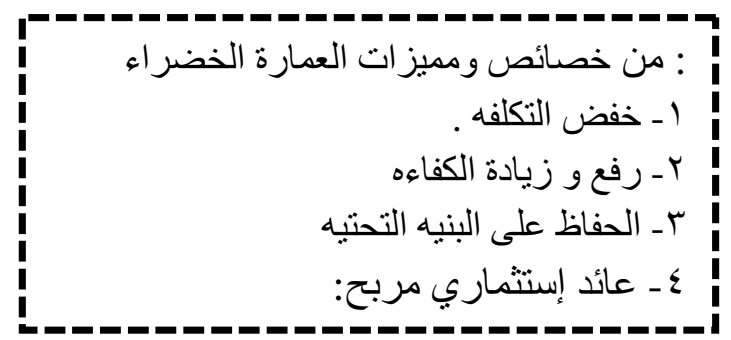

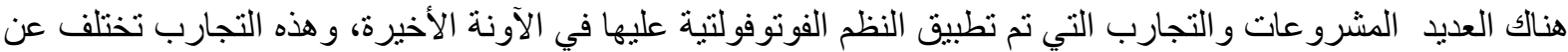

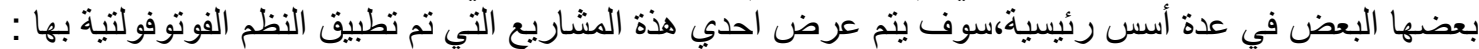

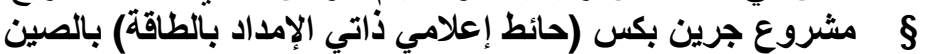

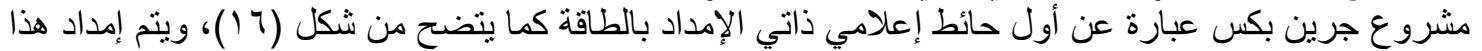

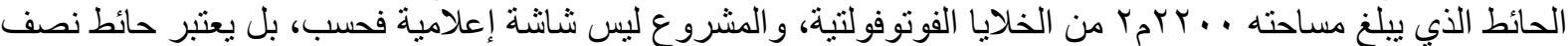

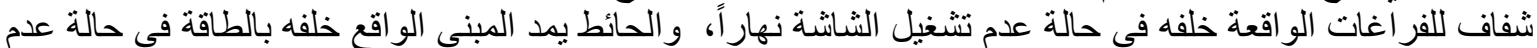

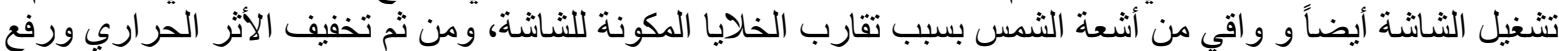

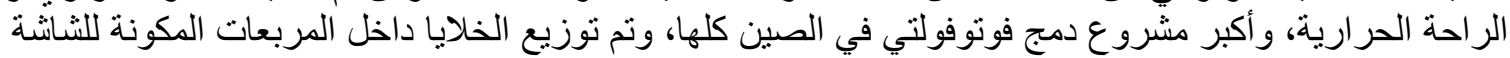

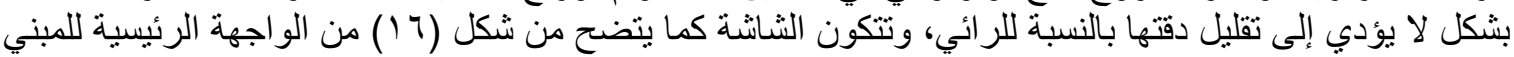

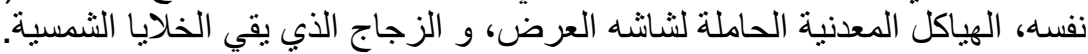

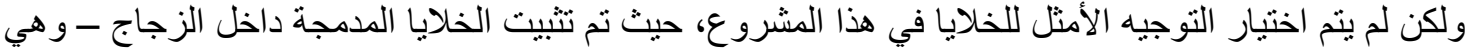

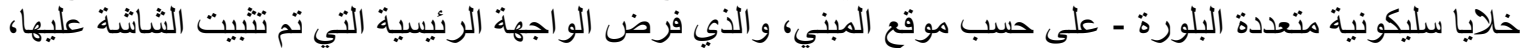

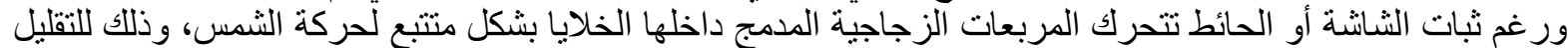

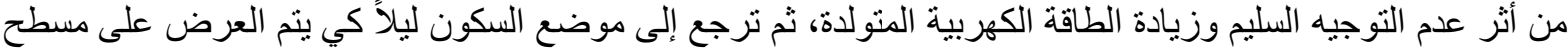

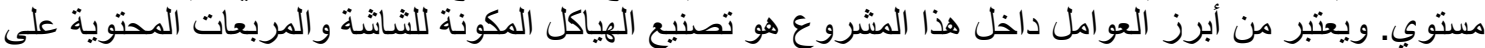

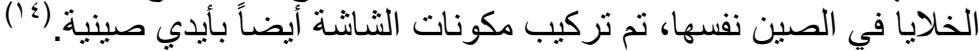
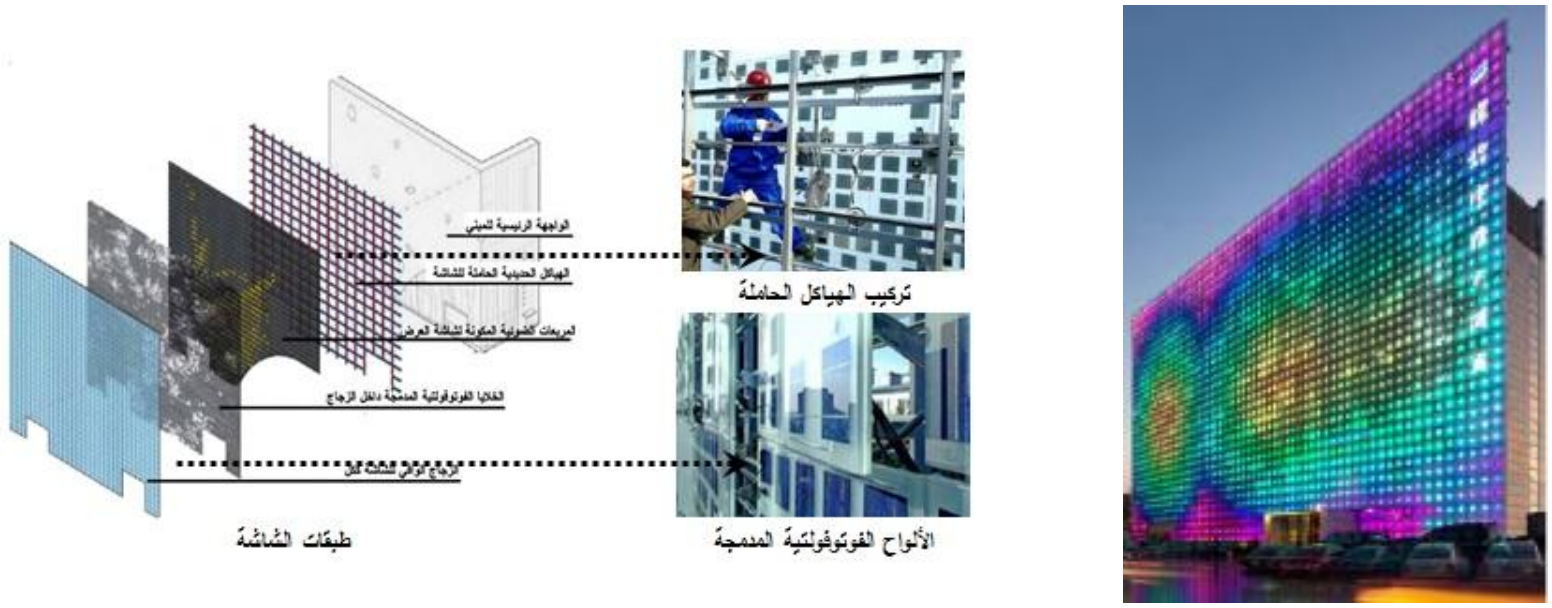

شكل (1 1 ): مكونات شاشة العرض في مشروع جرين بكس بالصين

Moamen El-Soudany, M., 2009. المصدر: 
V- طرق تقييم أداء النظم الفوتوفولتية المستخدمة في المباني.

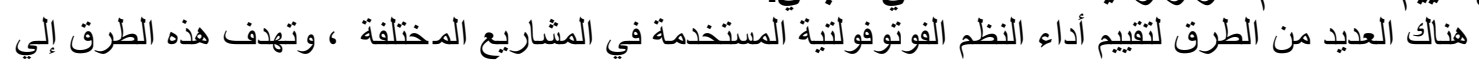

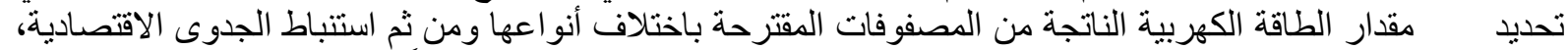

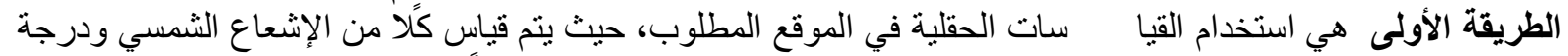

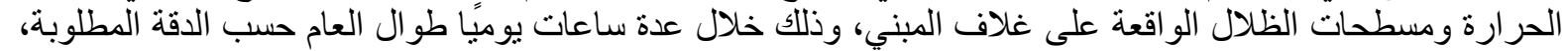

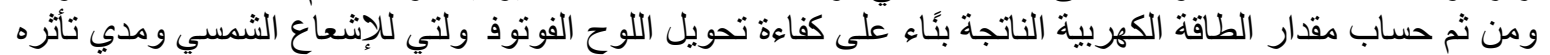

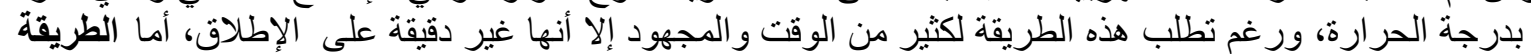

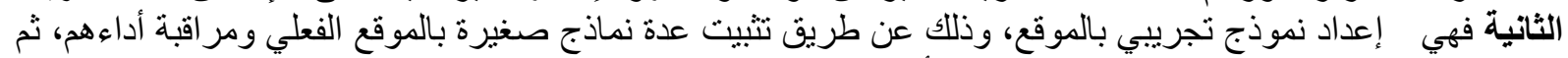

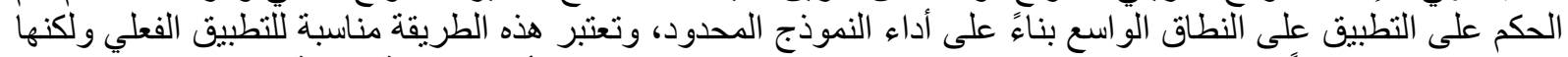

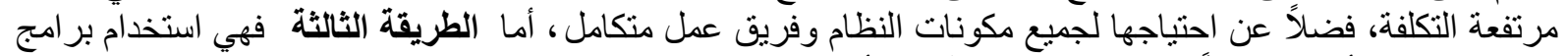

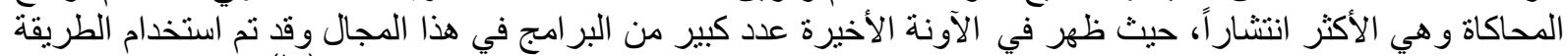

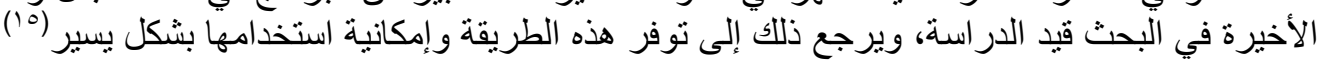

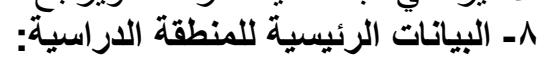

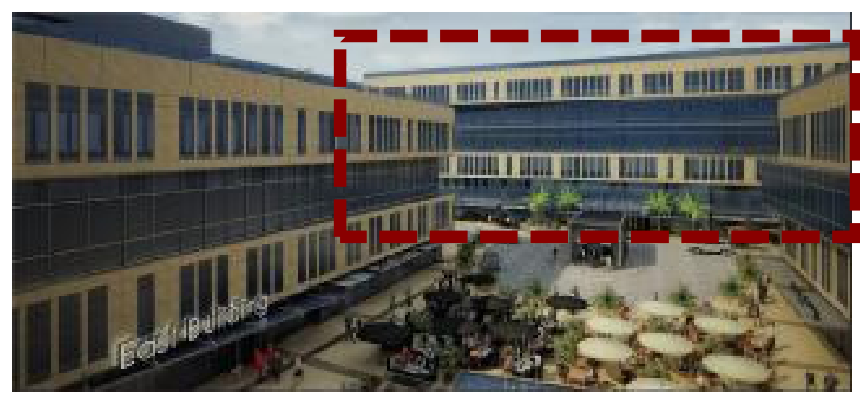

شكل (IV) (IV): مجمع مباني راية بلازا بمدينة ج أكتوبر

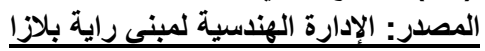

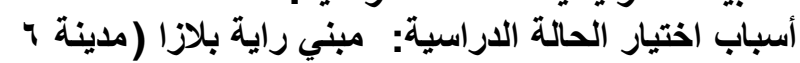

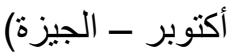

ا - مبني حاصل علي شهادة اللييد وبالتالي من أهدافه

تحسين كفاءة استخدام الطاقة

r- يصنف كمبني ذكي من خلاعل استخدامه لعناصر

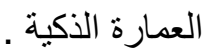

r- مبني حديث يستخدم في تقنياته تكنولوجيا النانو

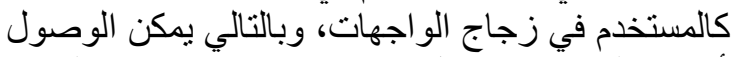

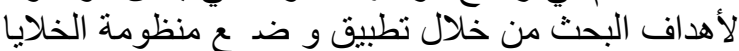

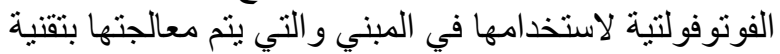
النانو تكنولوجي في محاولة لزيادة ورفع كفاء المبني و التقليل

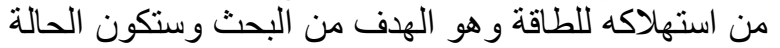

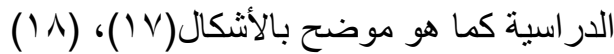

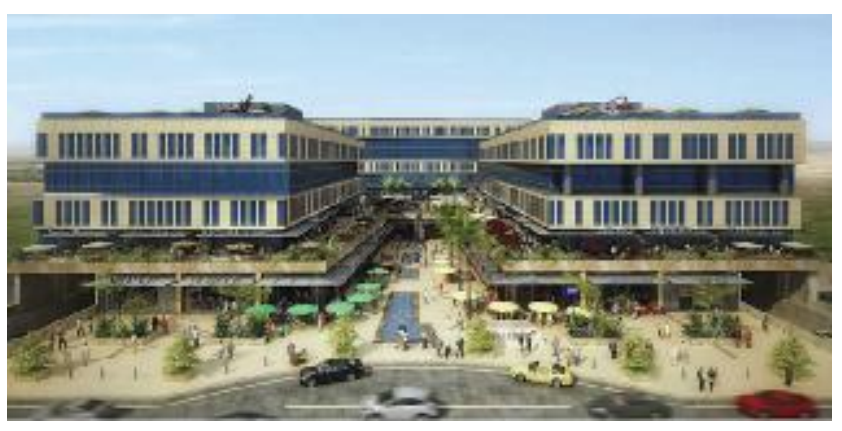

شكل (1 1 ): مبني راية بلازا حالة الدراسة المصدر: الإدارة الهندسية لمبني راية بلازا 


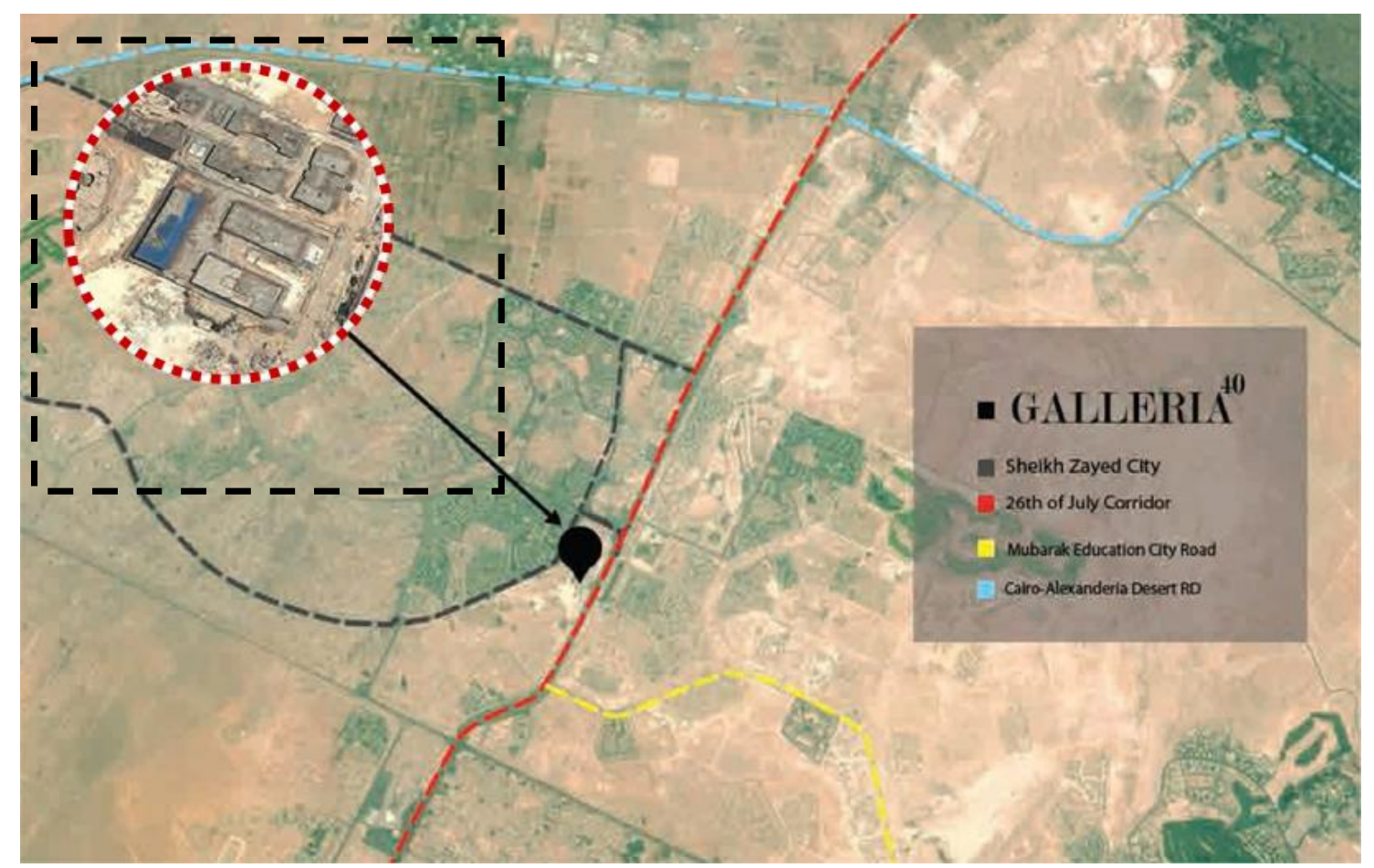

شكل (9 1 ): خريطة توضح منطقة الاراسة وحالة الاراسة مبني راية بلازا

وسيتم إلقاء الضوء على أهم الملادح التى تخص الدراسة في توضع مدينة 7 أكتوبر فيما ليلي:

التوصيف المناخي للمدينة

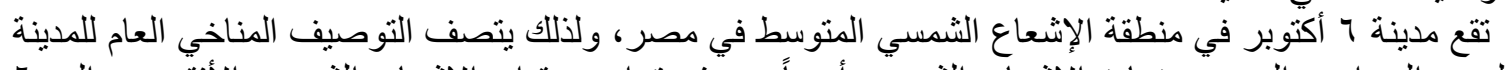

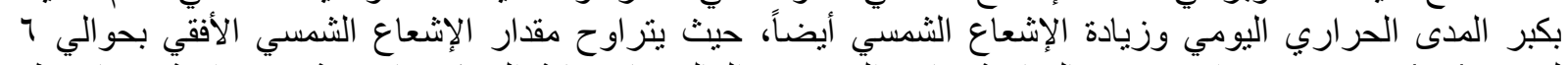

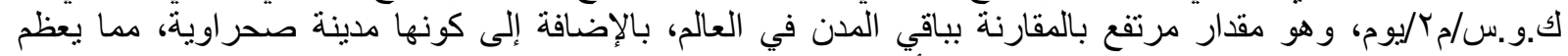

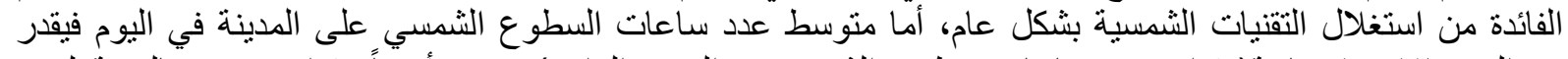

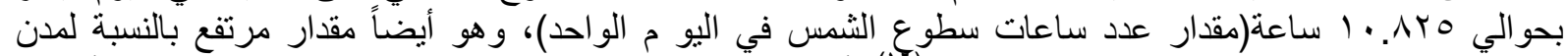

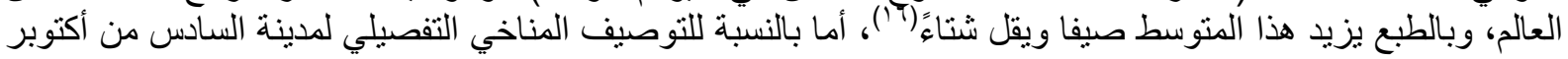
فيمكن تلخيصه في جدول (r) (r) 
جدول (r): التوصيف المناخي لمدينة السادس من أكتوبر (العناصر المؤثرة على النظم الفوتوفولتية) (Yl)

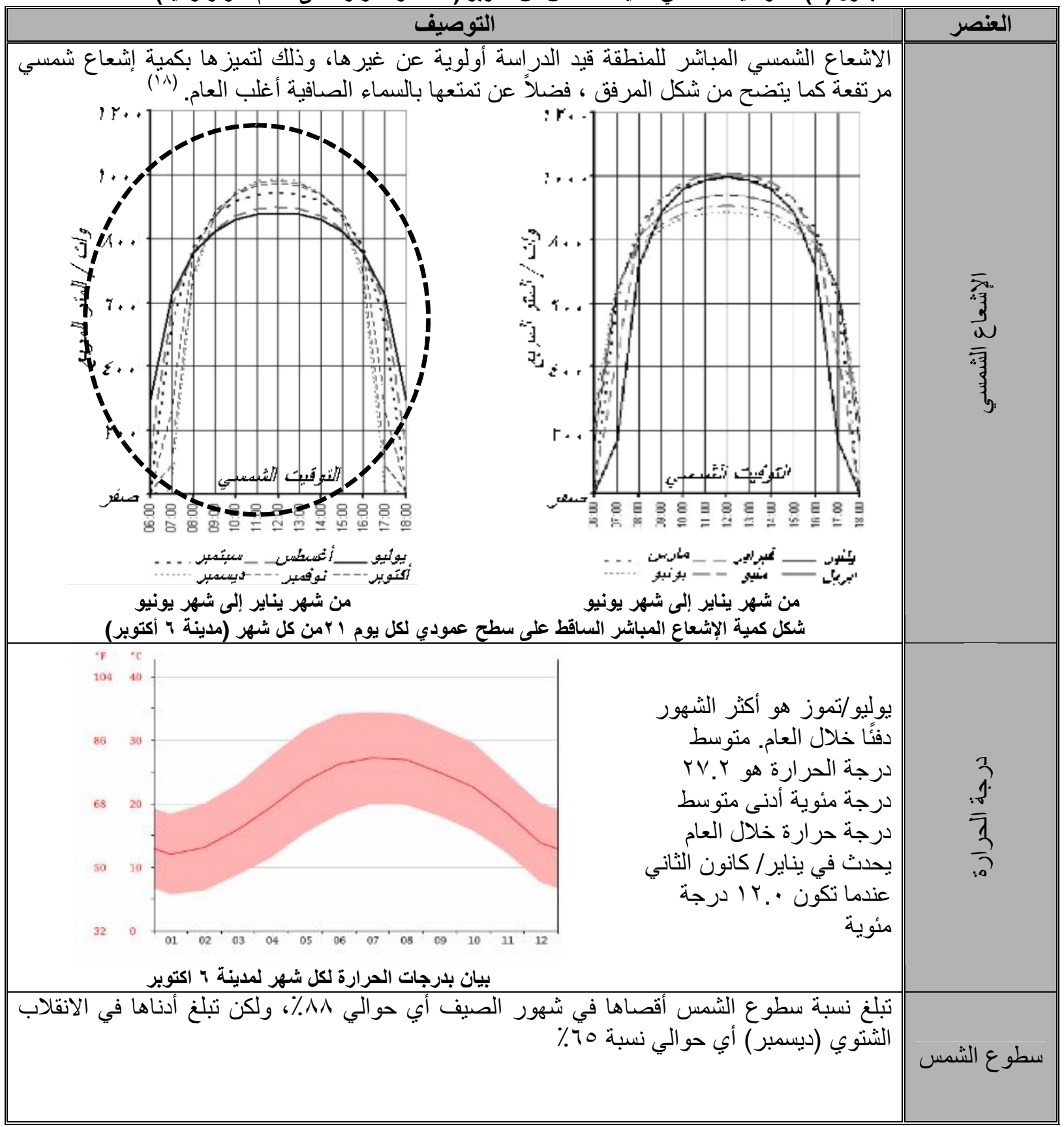




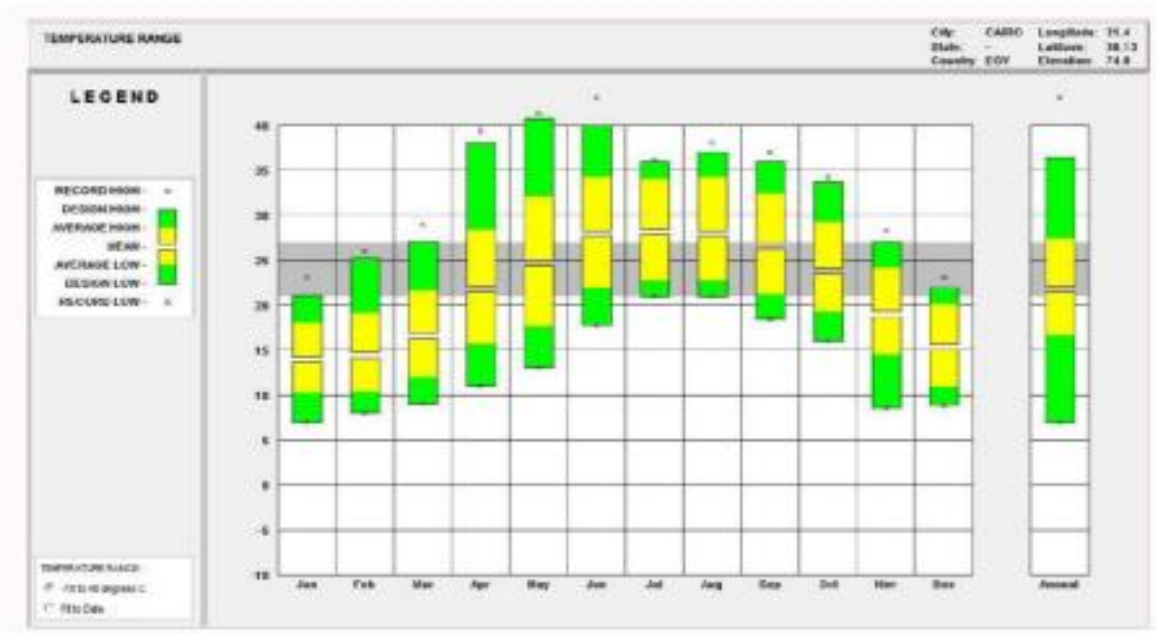

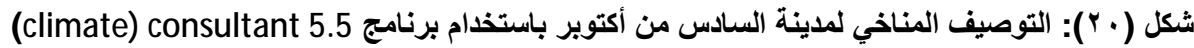
المصدر: تطبيقات تقنية النانو علي الزجاج ومدي تاثير ها علي كفاءة استخدام الطاقة في المباني الاداريةـ محمود عطية محمد علي كلي

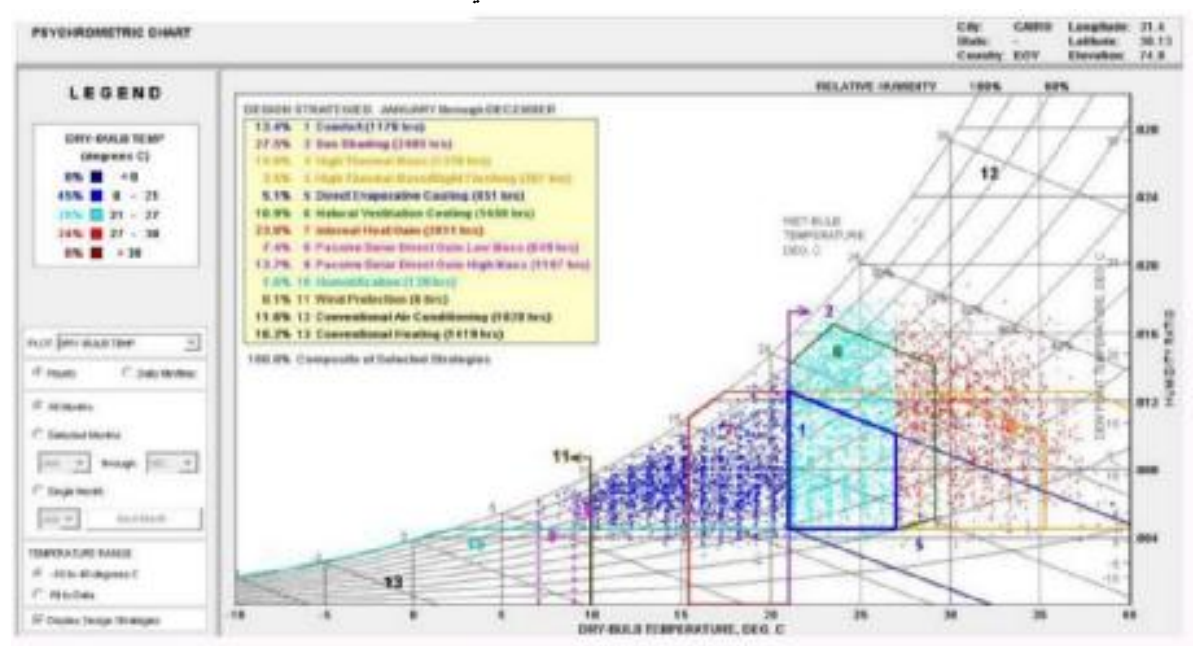

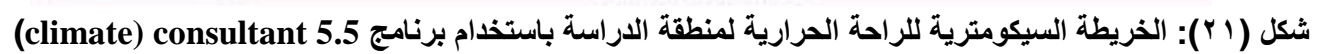
المصدر: تطبيقات تقنية النانو علي الزجاج ومدي تاثير ها علي كائية كفاءة استخدام الطاقة في المباني الادارية. محمود عطية محمد علي كلي

\section{حالة ا: توزيع المصفوفات على السطح بأسلوب تجميع مفتوح وتوجيه ثابت بالميل المثالي}

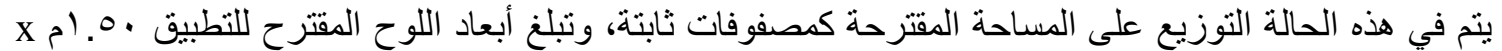

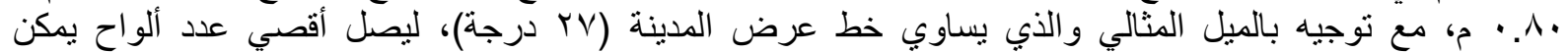

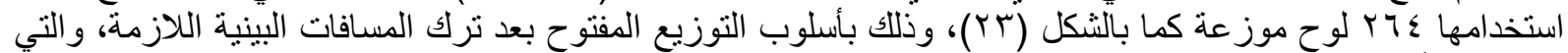

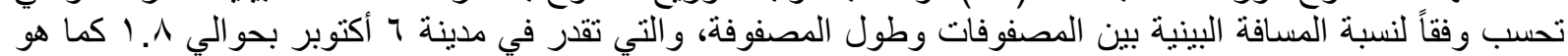

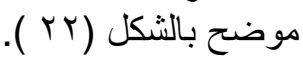

\section{حالة ب: توزيع المصفوفات على السطح بأسلوب تجميع مغلق وتوجيه متتبع بالميل المثالي}

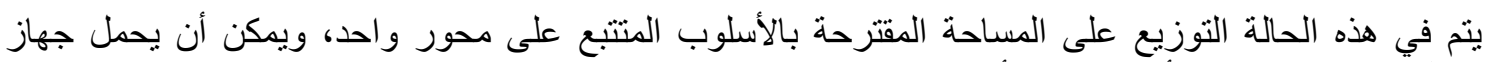

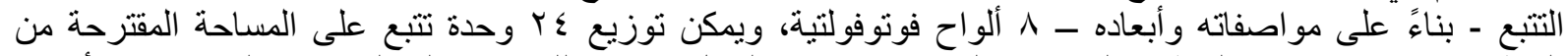

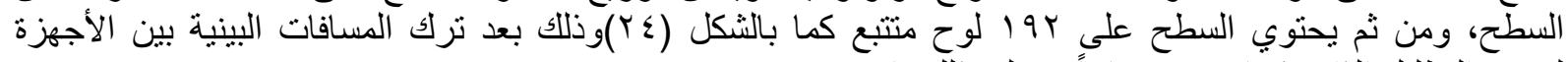
لتجنب التظليل الذاتي كما حسبت سابقاً، و علي ذللك فإن:

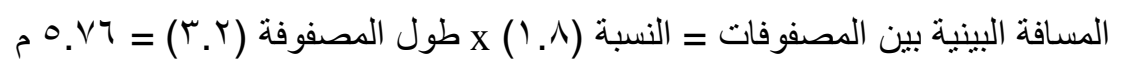


تقدير مقار الطاقة الناتج من النظام

تم تقدير مقدار الطاقة الكهربية المنتجة من الحالات السابقة باستخدام طرق الحساب الرياضية، بالإضافة إلى الى

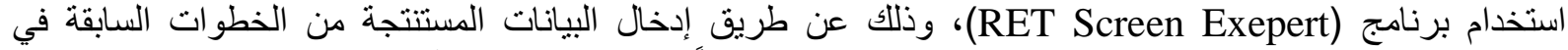
البرنامج، وتم حساب مقدار الطاقة الكهربية الناتج من النظام رياضياً حسب المعادلات النات الآتية:

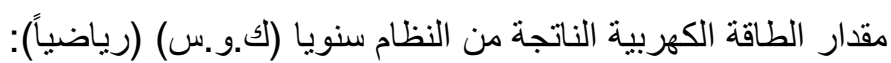

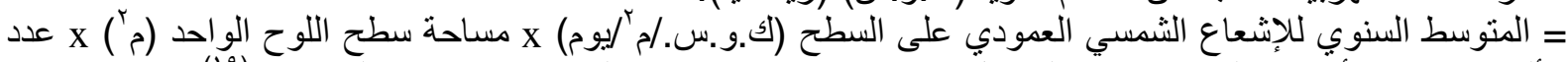

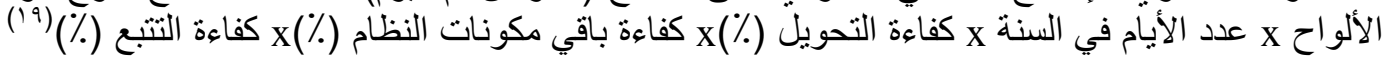

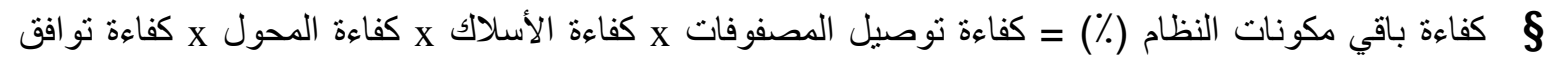

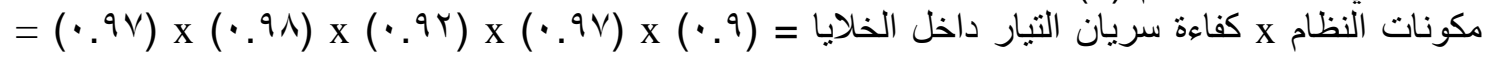

وبهذا يكون مقدار الطاقة الكهربية الناتج من النظام سنويا (م.و.س) (رياضيا):

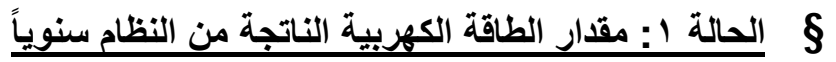

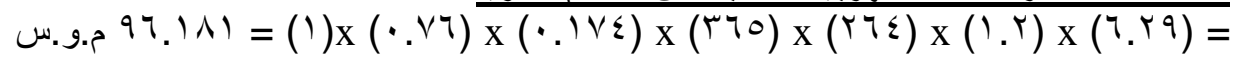

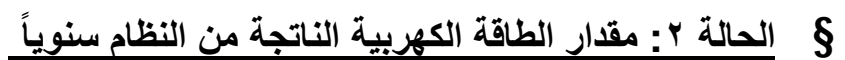

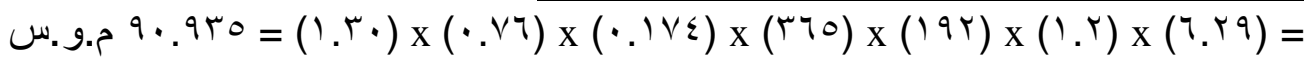
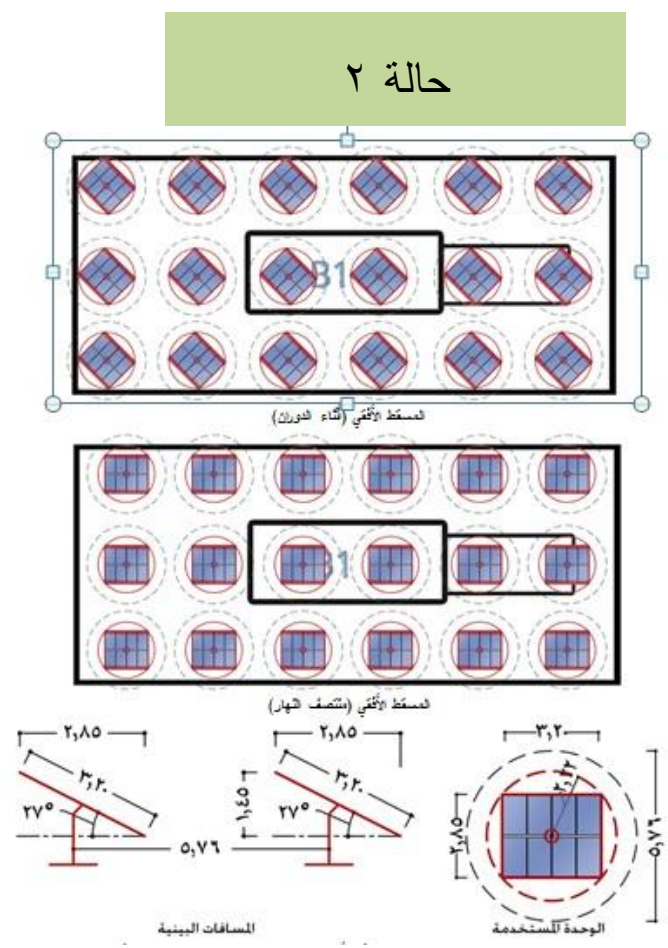

شكل (צ r): توزيع المصفوفات الفوتوفولتية بأسلوب

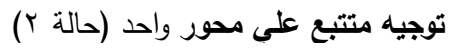

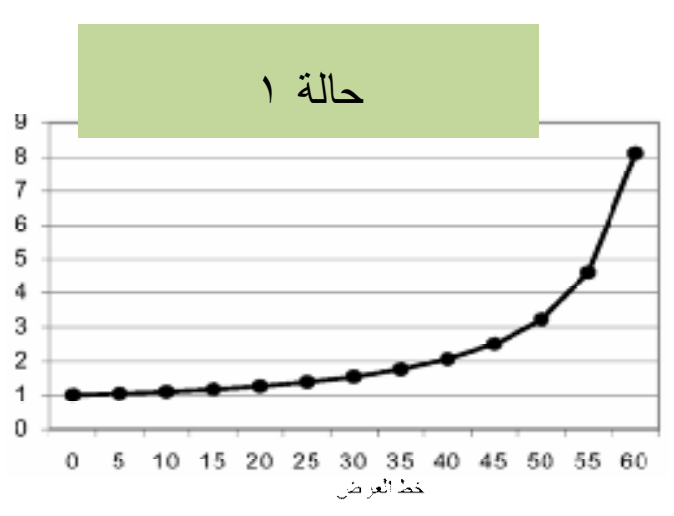

شكل (r r): علاقة المسافات البينية بين المصفوفات الثابتة بخط عرض المدينة (1)

وعلي ذلك فإن: الحالة (1):

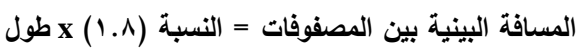

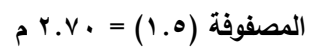

الحالة (ץ): المسافة البينية بين المصفوفات = النسبة X (1.^)

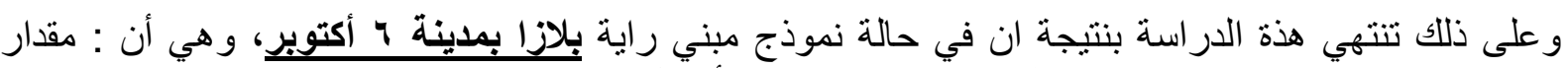

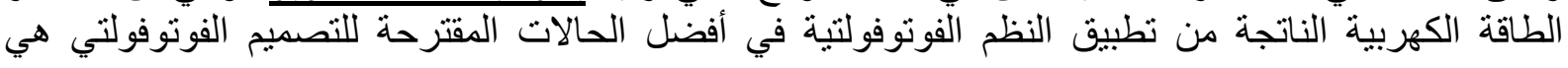


الحالة رقم ا، وان النظم الفوتوفولتية المصنعة بتكنولوجيا النانو إنتاجها للطاقة الكهربية اعلي من مثنلاتها العادية سواء حاليا أو علي مدار الخمس سنوات التي تلي استخدام النظم الفوتوفولتية.

شكل بr ب ت توزيع المصفوفات الفوتوغرافية

بأسلوب توجيه ثابت وتجميع مفتوح ( حالة الن )
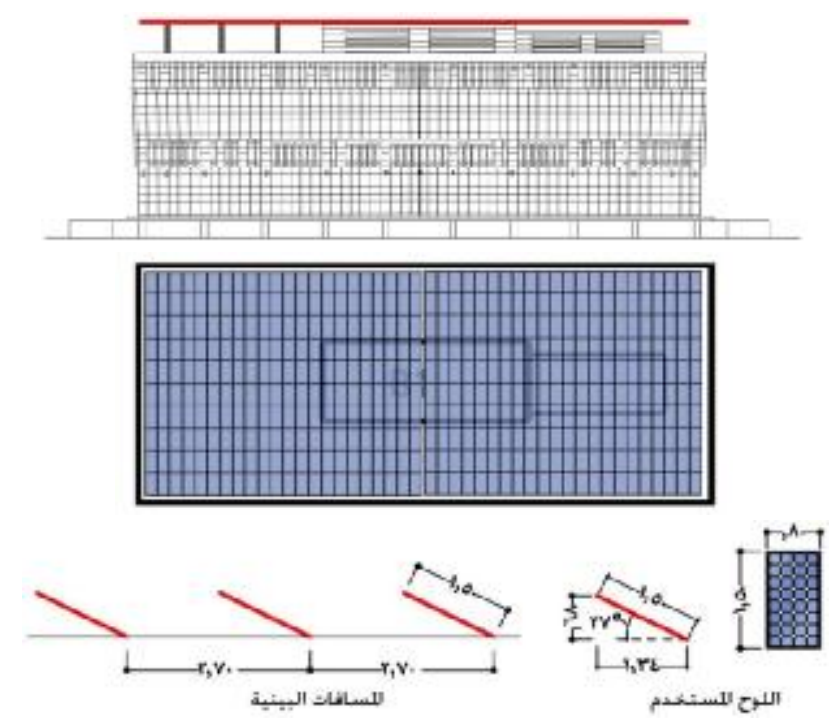

اد الاستدامة هو البداية الحقيقية للوصول للوصف و الفهم الصحيح لماهية

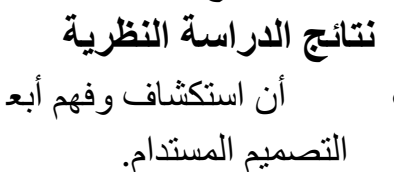

أنه لا بمكن تحقيق استدامة بيئية أو اجتماعية أو اقتصادية بشكل منفصل، بل لابد من أخذ الجو انب

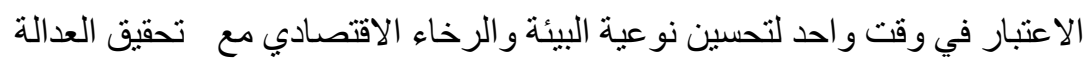

الأناثة بنظر بعين

الاجنماعية.

توجد خمسة مبادئ أساسية يتم الاعتماد عليها في العديد من نظم تقيبم المباني المستدامة في رسم

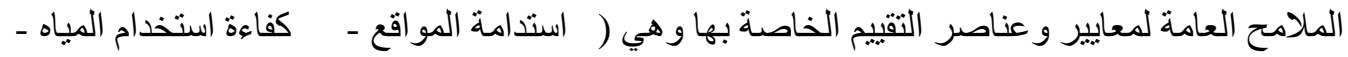

الحفاظ على الطاقة و الغلاف الجوي - جودة البيئة الداخلية ـ الحفاظ على الئى الموارد).

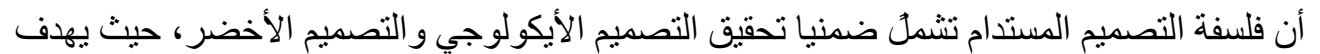

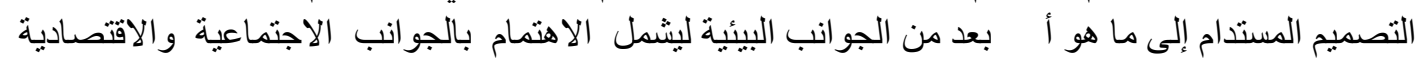

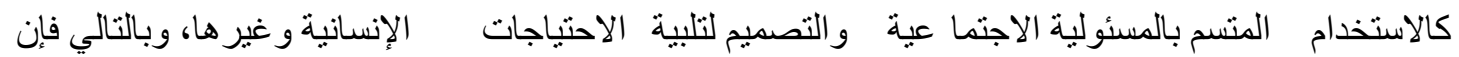

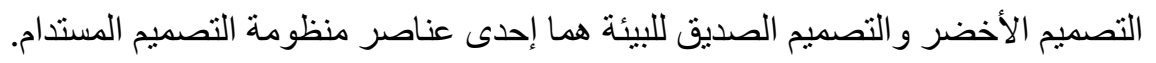

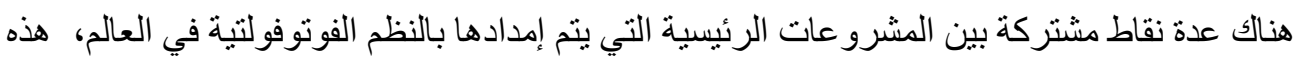

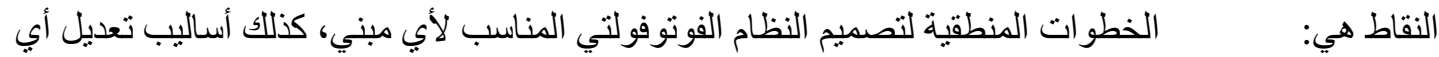

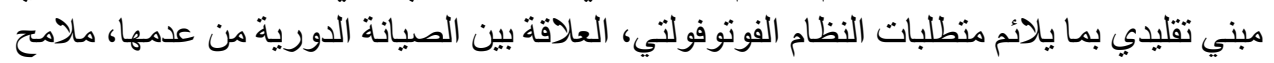

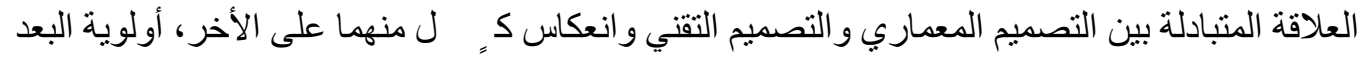

البيئي لاستخدام هذه النظم، و أهمية استخدام بر امج المحاكاة في اختبار جدوى استخدام هذه النظم النّا 
نجد من خلال در استنا لأنو اع الخلايا الثمسية التقليدية و الخلايا الثمسية المصنو عة بتقنية تكنولوجيا

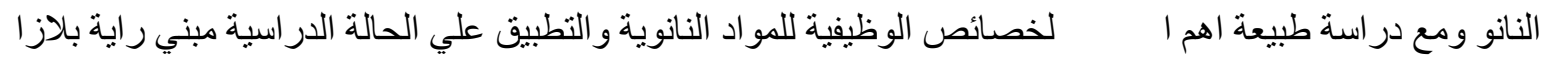
بمدينة 7 أكتوبر نستطيع درأن نلخص إلى النتائج التالية

جدول (ץ): مقارنة بين الخلايا الثمسية التقليدية والخلايا الثمسية النانونية والتي تظهر مدي كفاعة الخلايا الناونية

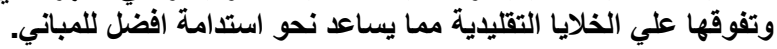

المصدر: الباحث

\begin{tabular}{|c|c|c|}
\hline الخلابا الثمسية بتقتبة تكنولوجيا النانو & الخلابا الثمسية التقبليدية & \\
\hline 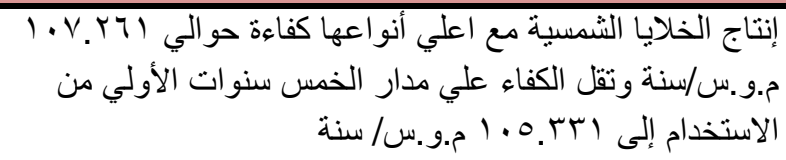 & 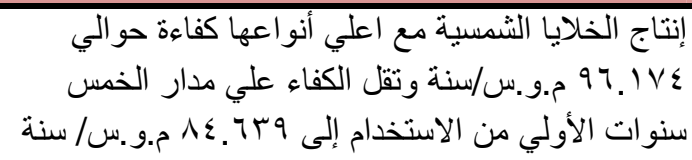 & $\frac{1}{4}$ \\
\hline 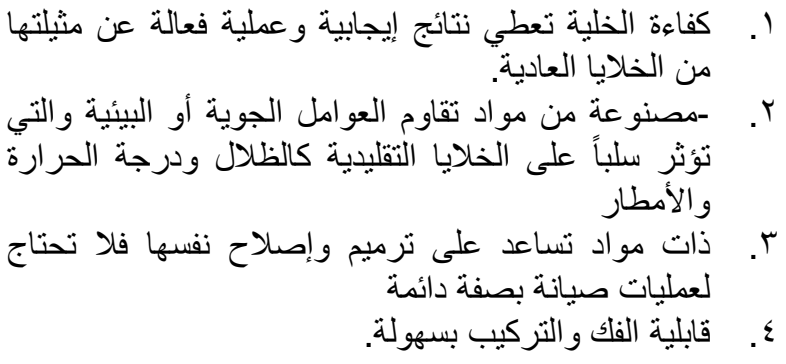 & 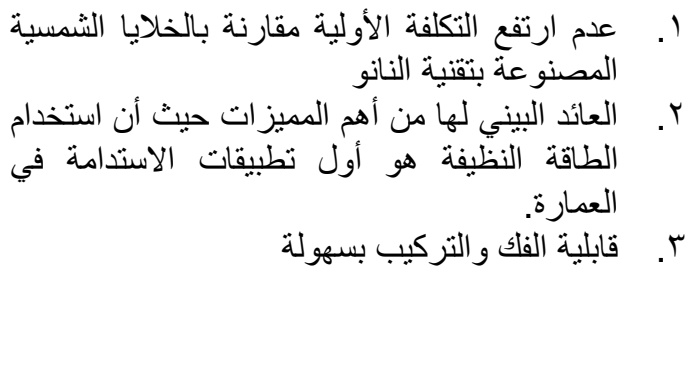 & $\overline{3}$ \\
\hline ا ـ للأتفرادة الأولية لا تزال مرتفعة وغير مجدية حاليا بالنسبـة & 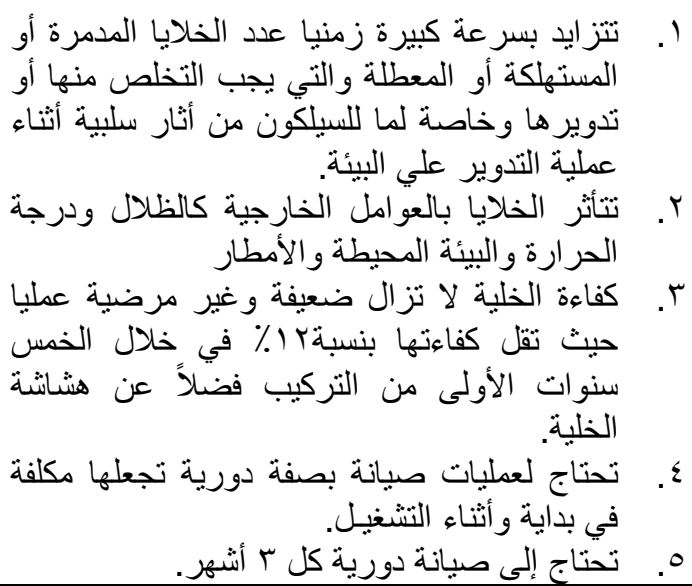 & $\overline{7}$ \\
\hline
\end{tabular}

ثانيا: التوصيات

فاهيم و أسس ومبادئ العمارة المستدامة و التصميم المستدام و التقنية النانوية

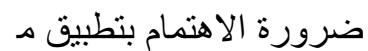

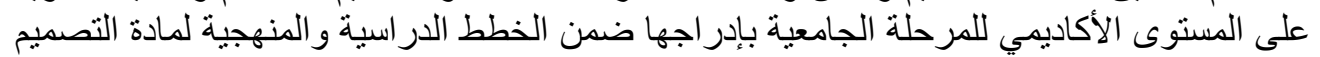

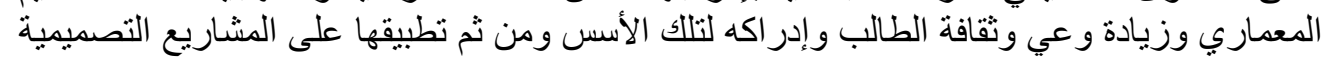

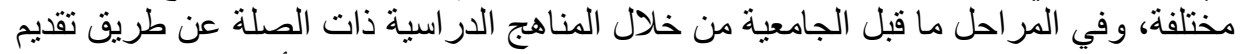

محتويات علمية بصورة شيقة ومبسطة عن ماهية تلك العلوم وما يمكن أن تسهم به في حياتنا

ضرورة ارتباط عمليات البحث العلمي في المجالات التقنية كالتقنية النانوية بالدر ال سات و البيانات الحديثة و الموثقة و التي تصَّدر دوريا عن طريق الهيئات و المؤسسات والثركات الإقليمية و الدولية المختصة ومز امنة الأبحاث العلمية مع تلك البيانة البهات. يوصي البحث الجهات المسئولة عن الطاقة بمصر بالاتجاه إلي استغلال الطاقة المتجددة، وذلك كبديل

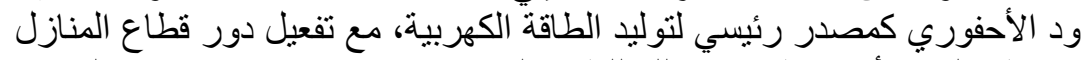

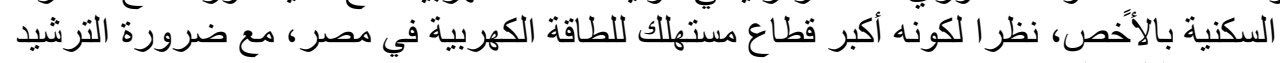

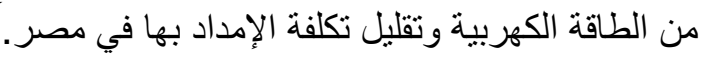

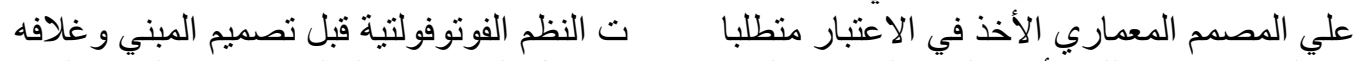
الخارجي، وكذلك الأمر بالنسبة لتخطيط المدن، ومن ثم جعل المباني مؤهلة لتطبيق هذه النظمّ عليها، 
وبالتالي تخليق علاقة تبادلية بين المصدم و المخطط و التقني للتوصل إلي مباني ذاتية الإمداد بالطاقة

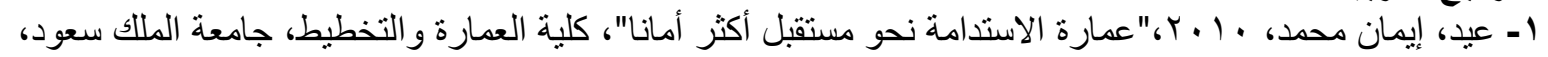

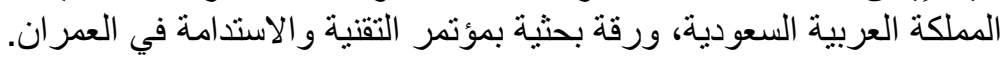

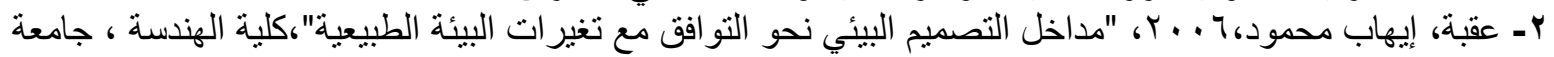

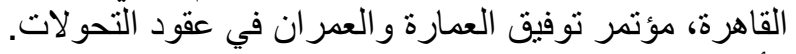

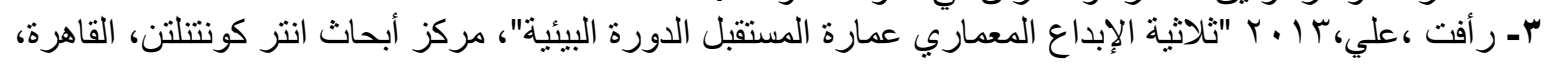

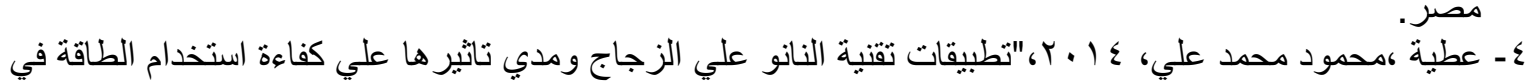

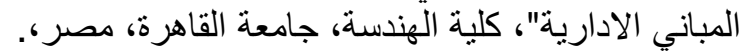

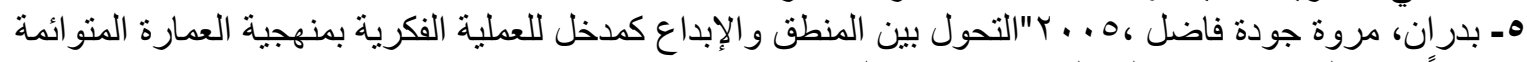

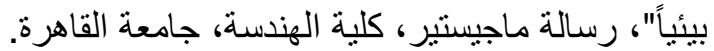

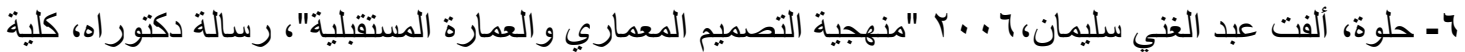

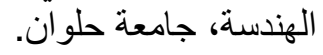

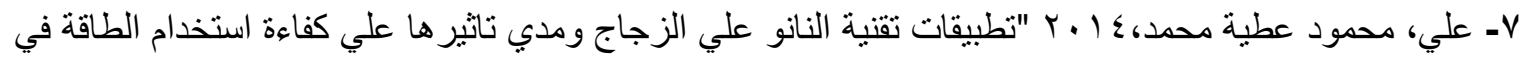

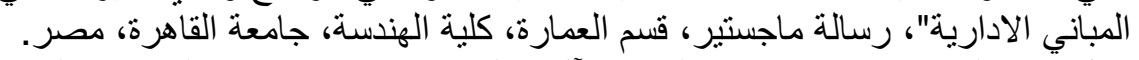

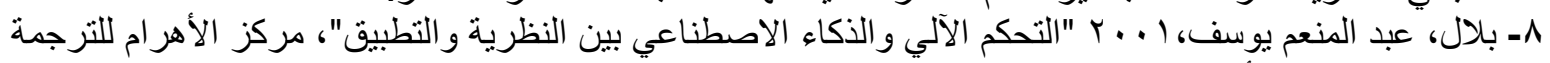
و النشر، مؤسسة الأهر ام-القاهرة.

المراجع الاجنبية

1-. National Institute of Building Sciences, (2009) "Whole Building Design guide site" http://bdg.org/design/sustainable.php

2- Charles Ibert, (2012) "Sustainable Construction Green Building design and Delivery" Nersey John Wiley Sons".

3- What is nanotechnology? 2013," European Commission". <http://ec.europa.eu/health/opinions2/en/nanotechnologies/1-3/1-introduction.htm>.

4- Ashby, M. F., and Daniel L. 2009"Schodek. Nanomaterials, nanotechnologies and design" an introduction for engineers and architects. Amsterdam: Butterworth-Heinemann,

6-. Somov, Pavel G. The lotus effect, 2010" Shedding suffering and rediscovering your essential self". Oakland, CA: New Harbinger Publications.

7- "Lotus effect - Mechanisms behind the Lotus effect, 2013." Atomic World, www.hkphy.org/atomic_world/lotus/lotus02_e.html

8- Atomic World 2013"Lotus effect - Mechanisms behind the Lotus effect." www.hkphy.org/atomic_world/lotus/lotus02_e.html.

9- MIT's News Office "Through a glass, clearly." ,2013, http://web.mit.edu/newsoffice/2012/glare-dust-and-fog-free-glass-0426.html 